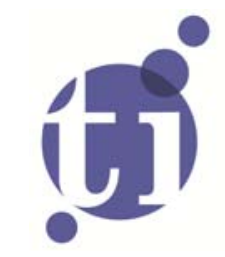

\title{
Dynamics and Determinants of Energy Intensity in the Service Sector: A Cross-Country Analysis, 1980-2005
}

Peter Mulder

Henri L.F. de Groot ${ }^{1,2,3}$

Birte Pfeiffer ${ }^{3}$

1 Faculty of Economics and Business Administration, VU University Amsterdam, The Netherlands;

2 Tinbergen Institute, The Netherlands;

3 Ecorys NEI, The Netherlands;

4 German Institute of Global and Area Studies Institute for African Affairs (IAA), Hamburg, Germany. 
Tinbergen Institute is the graduate school and research institute in economics of Erasmus University Rotterdam, the University of Amsterdam and VU University Amsterdam.

More TI discussion papers can be downloaded at http://www.tinbergen.nl

Tinbergen Institute has two locations:

Tinbergen Institute Amsterdam

Gustav Mahlerplein 117

1082 MS Amsterdam

The Netherlands

Tel.: +31(0)205251600

Tinbergen Institute Rotterdam

Burg. Oudlaan 50

3062 PA Rotterdam

The Netherlands

Tel.: +31(0)10 4088900

Fax: $+31(0) 104089031$

Duisenberg school of finance is a collaboration of the Dutch financial sector and universities, with the ambition to support innovative research and offer top quality academic education in core areas of finance.

DSF research papers can be downloaded at: http://www.dsf.nl/

Duisenberg school of finance

Gustav Mahlerplein 117

1082 MS Amsterdam

The Netherlands

Tel.: +31(0)20 5258579 


\title{
Dynamics and Determinants of Energy Intensity in the Service Sector: A Cross-Country Analysis, 1980-2005
}

\author{
Peter Mulder $^{\mathrm{a}, 1}$, Henri L.F. de Groot ${ }^{\mathrm{a}, \mathrm{b}, \mathrm{c}}$ and Birte Pfeiffer ${ }^{\mathrm{d}}$ \\ ${ }^{a}$ Department of Spatial Economics, VU University Amsterdam, Amsterdam, The Netherlands \\ ${ }^{\mathrm{b}}$ Tinbergen Institute, Amsterdam-Rotterdam, The Netherlands \\ ${ }^{\mathrm{c}}$ Ecorys NEI, Rotterdam, The Netherlands \\ ${ }^{\mathrm{d}}$ GIGA German Institute of Global and Area Studies \\ Institute for African Affairs (IAA), Hamburg, Germany
}

\begin{abstract}
We present a detailed analysis of energy intensity developments across 23 service sectors in 18 OECD countries over the period 1980-2005. We find that the shift towards a service economy has contributed to lower overall energy intensity levels in the OECD, but this contribution would have been considerably larger if the service sector had realized the same degree of energy efficiency improvements as the manufacturing sector. In most OECD countries actual energy intensity levels in the service sector tend to decrease relatively slow, especially after 1995 . If we control this trend for the impact of structural changes within the services sector - by means of a decomposition analysis - we find that in about one-third of the OECD countries, energy intensity levels in the service sector have increased over time. The impact of structural changes on aggregate energy intensity dynamics in the service sector has increased considerably after 1995, highlighting a relatively poor energy efficiency performance within a wide range of service sectors. We show that the introduction of Information and Communication Technology (ICT) plays a potentially important role here. Using spatial panel data regression analysis, we find a limited role for energy prices in explaining variation in energy productivity, casting doubt on the effectiveness of price instruments to enhance energy efficiency in the service sector. In contrast, climate conditions have a clear impact on energy productivity, especially the number of heating days.
\end{abstract}

Keywords: energy intensity, convergence, decomposition, sectoral analysis, service sector JEL codes: O13, O47, O5, Q43

\footnotetext{
${ }^{1}$ Corresponding author: Peter Mulder, Department of Spatial Economics, VU University Amsterdam, De Boelelaan 1105, 1081 HV Amsterdam, The Netherlands, e-mail: p.mulder@vu.nl. This research is in part an outgrowth of a project carried out by Peter Mulder and Henri de Groot at CPB Netherlands Bureau for Economic Policy Analysis and financially supported by the Ministry of Economic Affairs as part of the project 'Environmental Economics and Policy'. The support of CPB Netherlands Bureau for Economic Policy Analysis and the Ministry of Economic Affairs is gratefully acknowledged. We are grateful to Adriaan van Hien for his excellent support in the construction of the database. Without implication, useful comments by Rob Aalbers, Casper van Ewijk, Hein Mannaerts and Herman Vollebergh at various stages of the research are gratefully acknowledged.
} 


\section{Introduction}

Climate change and energy security are among the major challenges facing the world economy in the 21 st century. In view of these challenges, surprisingly little is known about energy efficiency in the service sector. Existing studies that study energy efficiency dynamics across countries traditionally focus on the energy intensive industries in the manufacturing sector (see, for example, Howarth et al. 1991, Eichhammer and Mannsbart 1997, Miketa and Mulder 2005, Mulder and De Groot 2007, Unander 2007, Park et al. 1993). ${ }^{2}$ The typically held view is that the service sector is of less importance given its relatively limited use of energy. Furthermore, it is often assumed that the sectoral transition from manufacturing towards services in developed countries may serve to alleviate the environmental and security concerns related to the use of energy. This view on energy use in the service sector may, however, be challenged for at least two reasons. First, across the world the service sector is growing relatively fast (in absolute terms and as a share of GDP) as economic development proceeds, which obviously lead to a relatively fast growth of energy consumption in the service sector. Second, energy consumption patterns in the service sector change as a result of the fact that production processes within the service sector have undergone drastic changes, most notably in response to the advent of Information and Communication Technology (ICT). Depending on which trends prevail, future policies for that matter will have to take the service sector serious in efforts aimed at developing a sustainable future economic development.

Against this background, this paper presents a detailed analysis of the evolution of energy intensity (i.e., the ratio of energy input to economic output) in the service sector for 18 OECD countries over the period 1980-2005. Together, in 2005 these 18 countries are responsible for nearly $65 \%$ of world GDP and world energy consumption in the service sector. Typically, cross-country studies come at the price of limited sectoral detail, which may mask substantial heterogeneity in output and productivity growth within the aggregate sector (see, for example, Huntington 2010, Jorgenson 1984, Mulder and De Groot 2007). In contrast, using a new database, we combine our cross-country perspective with a high level of sector detail, distinguishing 23 subsectors in services. To the best of our knowledge, we are the first to analyze the energy intensity developments in the service sector with this degree of sectoral, crosssectional and temporal coverage. We document and compare both levels and growth rates of energy intensity, and identify to what extent aggregate energy dynamics in the service sector can be explained from, respectively, technological progress and shifts in the underlying sector structure. Finally, we identify determinants of the observed energy intensity trends, with special attention for the role of ICT.

Tables 1 and 2 present some first evidence on the dynamics in the service sector, which substantiates the increasing relevance of the service sector in terms of energy consumption and energy dynamics. Table 1 shows the evolution of the relative weight of the service sector in the total economy over time, both in terms of value added and energy consumption. It can be seen that across the 18 OECD countries in our sample, in 2005 the service sector is responsible for about two-third of total value added and one-fifth of total energy consumption. Interestingly, Table 1 shows that the value added share has increased at a fairly

\footnotetext{
${ }^{2}$ Recent exceptions include Florax et al. (2011), Huntington (2010), and Mairet and Decellas (2009).
} 
modest speed over time, whereas the energy share has increased considerably - even up to $25 \%$ in main Western European countries (EU6) and Japan. ${ }^{3}$

Table 1. Share of the service sector in the total economy

\begin{tabular}{|c|c|c|c|c|c|c|c|c|}
\hline & \multicolumn{6}{|c|}{ Level } & \multicolumn{2}{|c|}{ Change (in \%) } \\
\hline & \multicolumn{3}{|c|}{ Value added (in \%) } & \multicolumn{3}{|c|}{ Energy (in \%) } & \multirow{2}{*}{$\begin{array}{l}\text { Value added } \\
1995-2005 \\
\end{array}$} & \multirow{2}{*}{$\frac{\text { Energy }}{1995-2005}$} \\
\hline & 1980 & 1995 & 2005 & 1980 & 1995 & 2005 & & \\
\hline USA & 65 & 68 & 68 & 14 & 16 & 18 & 0 & 13 \\
\hline JPN & 55 & 58 & 60 & 11 & 18 & 23 & 5 & 25 \\
\hline OECD9 & 62 & 66 & 67 & 14 & 16 & 18 & 1 & 18 \\
\hline EU6 & 62 & 68 & 70 & 12 & 13 & 16 & 3 & 25 \\
\hline OECD18 & - & 66 & 67 & - & 16 & 18 & 1 & 15 \\
\hline EU15 & - & 67 & 69 & - & 15 & 17 & 2 & 11 \\
\hline EU4 & - & 70 & 66 & - & 22 & 19 & -6 & -15 \\
\hline
\end{tabular}

Source: See Mulder and De Groot (2012) and Section 2 for details on the dataset.

Table 2 provides for the various (clusters of) countries and different time periods studied in this paper the average annual growth rates of energy intensity in the service sector, in comparison with energy intensity growth rates in the total economy and the manufacturing sector. The table clearly reveals that the decline in manufacturing energy intensity levels has been substantially larger than the decline in services energy intensity levels, especially in the period after 1995. The service sector shows a very modest decrease in energy intensity levels at best. An exception to this pattern is the service sector in Japan, which is even characterized by a persistent and considerable increase in energy intensity over time, especially in the period 1980-1995. Also, the group of four new EU member states (former Eastern Europe) is somewhat special in that they exhibit a relatively strong decrease in energy intensity between 1995-2005, presumably because of a catching-up effect following their turn to market economies (cf. Markandya et al. 2006, Mulder and De Groot 2012). Nevertheless, even in the EU4 sample, the decline in services energy intensity levels has been relatively small - less than half of the decrease in the manufacturing sector. Together with the relatively rapid increasing energy share of the service sector (Table 1), this trend - if continued - implies that the emergence of a service economy is not automatically good news from an energy consumption point of view.

\footnotetext{
3 The cluster of four formerly Eastern European countries (EU4) is an exception in that in those countries on average the relative size of the Service sector has declined between 1995 and 2005, especially in terms of energy consumption. This is due to exceptional growth of the manufacturing sector in these countries, following their turn to market economies at the beginning of the 1990s.
} 
Table 2. Energy intensity growth rates across sectors and time periods

\begin{tabular}{|c|c|c|c|c|c|c|c|c|c|c|c|c|}
\hline & \multicolumn{9}{|c|}{ Average annual growth rate } & \multicolumn{3}{|c|}{$\begin{array}{c}\text { Growth difference Service } \\
\text { and Manufacturing* }\end{array}$} \\
\hline & \multicolumn{3}{|c|}{$1980-2005$} & \multicolumn{3}{|c|}{$1980-1995$} & \multicolumn{3}{|c|}{$1995-2005$} & $\begin{array}{c}1980 \\
-2005 \\
\end{array}$ & $\begin{array}{c}1980 \\
-1995 \\
\end{array}$ & $\begin{array}{c}1995 \\
-2005 \\
\end{array}$ \\
\hline & SRV & MAN & TOT & SRV & MAN & TOT & SRV & MAN & TOT & $\begin{array}{l}\text { SRV- } \\
\text { MAN }\end{array}$ & $\begin{array}{l}\text { SRV- } \\
\text { MAN }\end{array}$ & $\begin{array}{l}\text { SRV- } \\
\text { MAN }\end{array}$ \\
\hline USA & -1.8 & -3.7 & -2.4 & -2.2 & -2.0 & -2.3 & -1.3 & -6.4 & -2.6 & -1.9 & 0.2 & -5.0 \\
\hline JPN & 1.8 & -2.5 & -0.8 & 2.5 & -2.5 & -0.6 & 0.8 & -2.5 & -1.0 & -4.4 & -5.1 & -3.3 \\
\hline OECD9 & -0.7 & -2.8 & -1.9 & -1.3 & -1.9 & -1.9 & -0.4 & -4.3 & -1.9 & -2.1 & -0.5 & -3.8 \\
\hline EU6 & -0.7 & -1.5 & -1.3 & -1.4 & -0.8 & -1.1 & 0.3 & -1.8 & -1.5 & -0.8 & 0.6 & -2.1 \\
\hline OECD18 & - & - & - & - & - & - & -0.6 & -4.0 & -1.9 & - & - & -3.4 \\
\hline EU15 & - & - & - & - & - & - & -0.9 & -2.0 & -1.8 & - & - & -1.1 \\
\hline EU4 & - & - & - & - & - & - & -2.4 & -5.2 & -1.4 & - & - & -2.8 \\
\hline
\end{tabular}

Source: See Mulder and De Groot (2012) and Section 2 for details on the dataset.

* A negative difference means that the decrease in the energy intensity growth rate in services is smaller than in manufacturing. SRV= Services; MAN = Manufacturing; TOT = Total Economy (SRV+MAN+Construction+Agriculture). We refer to Table 4 for the country groupings.

The setup of this paper is as follows. In Section 2 we describe our data. Section 3 presents stylized facts on levels and changes in energy consumption and energy intensity across countries, in both the aggregate service sector and its various subsectors. In Section 4 we present the results of a decomposition analysis that separates the role of technological progress from shifts in the underlying sector structure in driving aggregate energy intensity dynamics in the service sector. This exercise yields insights into the realized potential of energy saving technological progress during the period 1980-2005 - which is, for example, of great interest in view of maintained arguments that energy saving is particularly difficult in energy extensive sectors (see, for example, Florax et al. 2011). We complete our analysis in Section 5 with a panel data regression analysis aiming to identify key determinants of cross-sectional and temporal energy intensity dynamics in the service sector, with special attention for the potential role of the emergence of Information and Communication Technology (ICT) after 1995. Section 6 concludes.

\section{Data description}

We make use of a new dataset developed by Mulder and De Groot (2012), which is based on the EU KLEMS database (O'Mahony and Timmer 2009). The latter contains sector-specific measures of output, inputs and productivity, derived from a consistent framework of national accounts and supply-and-use tables, and processed according to agreed procedures by EU KLEMS consortium partners with cooperation of national statistical offices. Since the EU KLEMS database includes information on energy inputs, our analysis does not rely on an ad-hoc combination of energy data and economic data from different sources, which typically characterizes empirical cross-country studies in the field of energy economics (see, for example, Duro et al. 2010, Duro and Padilla 2011, Mairet and Decellas 2009, Miketa 
and Mulder 2005, Mulder and De Groot 2007, Unander 2007). Another major advantage of this dataset is its high level of sector detail, which enables us to make a consistent comparison of sector-specific energyintensity trends across countries.

In this study we consider 23 service sectors ( 9 main sectors and 14 subsectors), as listed in Table 3. In terms of geographical coverage, our dataset includes 18 OECD countries: 11 EU-15 countries (Austria, Belgium, Denmark, Finland, France, Germany, the Netherlands, Portugal, Spain, Sweden and the United Kingdom), four new EU member states (Czech Republic, Hungary, Poland and Slovakia), the USA, Japan and South Korea. Our study covers the period 1980-2005. However, because of data availability and the rise of ICT since 1995, we distinguish in our analysis the periods 1980-1995 (for nine countries) from the period 1995-2005 (for 18 countries). To ensure comparability of data across countries, we cluster countries in various groups, as listed in Table 4.

Table 3. Sector classification of the service sector

\begin{tabular}{ll}
\hline Sector & NACE \\
WHOLESALE AND RETAIL TRADE & $\mathrm{G}$ \\
Sale, maintenance and repair of motor vehicles and motorcycles; retail sale of fuel & 50 \\
Wholesale trade and commission trade, except of motor vehicles and motorcycles & 51 \\
Retail trade, except of motor vehicles and motorcycles; repair of household goods & 52 \\
HOTELS AND RESTAURANTS & $\mathrm{H}$ \\
POST AND TELECOMMUNICATIONS & 64 \\
FINANCIAL INTERMEDIATION & $\mathrm{J}$ \\
Financial intermediation, except insurance and pension funding & 65 \\
Insurance and pension funding, except compulsory social security & 66 \\
Activities related to financial intermediation & 67 \\
RENTING, COMPUTER, R\&D and OTHER BUSINESS & 71 to 74 \\
Renting of machinery and equipment & 71 \\
Computer and related activities & 72 \\
Research and development & 73 \\
Other business activities & 74 \\
PUBLIC ADMIN AND DEFENCE; COMPULSORY SOCIAL SECURITY & $\mathrm{L}$ \\
EDUCATION & $\mathrm{M}$ \\
HEALTH AND SOCIAL WORK & $\mathrm{N}$ \\
OTHER COMMUNITY, SOCIAL AND PERSONAL SERVICES & $\mathrm{O}$ \\
Sewage and refuse disposal, sanitation and similar activities & 90 \\
Activities of membership organizations nec & 91 \\
Recreational, cultural and sporting activities & 92 \\
Other service activities & 93 \\
\hline
\end{tabular}




\begin{tabular}{|c|c|c|c|c|c|c|c|}
\hline & \multirow[b]{3}{*}{ Country } & \multirow[b]{3}{*}{ Code } & \multicolumn{5}{|c|}{ Country groups used in this study } \\
\hline & & & \multicolumn{2}{|c|}{$1980-2005$} & \multicolumn{3}{|c|}{ 1995-2005 } \\
\hline & & & OECD9 & EU6 & OECD18 & EU4 & EU15 \\
\hline 1 & Austria & AUT & $\checkmark$ & $\checkmark$ & $\checkmark$ & & $\checkmark$ \\
\hline 2 & Belgium & BEL & & & $\checkmark$ & & $\checkmark$ \\
\hline 3 & Czech Republic & $\mathrm{CZE}$ & & & $\checkmark$ & $\checkmark$ & $\checkmark$ \\
\hline 4 & Denmark & DNK & $\checkmark$ & $\checkmark$ & $\checkmark$ & & $\checkmark$ \\
\hline 5 & Finland & FIN & $\checkmark$ & $\checkmark$ & $\checkmark$ & & $\checkmark$ \\
\hline 6 & France & FRA & $\checkmark$ & $\checkmark$ & $\checkmark$ & & $\checkmark$ \\
\hline 7 & Germany & GER & & & $\checkmark$ & & $\checkmark$ \\
\hline 8 & Hungary & HUN & & & $\checkmark$ & $\checkmark$ & $\checkmark$ \\
\hline 9 & Japan & JPN & $\checkmark$ & & $\checkmark$ & & \\
\hline 10 & Korea & KOR & $\checkmark$ & & $\checkmark$ & & \\
\hline 11 & The Netherlands & NLD & & & $\checkmark$ & & $\checkmark$ \\
\hline 12 & Poland & POL & & & $\checkmark$ & $\checkmark$ & $\checkmark$ \\
\hline 13 & Portugal & PRT & & & $\checkmark$ & & $\checkmark$ \\
\hline 14 & Spain & SPA & $\checkmark$ & $\checkmark$ & $\checkmark$ & & $\checkmark$ \\
\hline 15 & Slovakia & SVK & & & $\checkmark$ & $\checkmark$ & $\checkmark$ \\
\hline 16 & Sweden & SWE & & & $\checkmark$ & & $\checkmark$ \\
\hline 17 & United Kingdom & UK & $\checkmark$ & $\checkmark$ & $\checkmark$ & & $\checkmark$ \\
\hline 18 & United States & USA & $\checkmark$ & & $\checkmark$ & & \\
\hline
\end{tabular}

We measure energy intensity by the ratio of intermediate energy input to gross value added. Value added data originate from National Accounts and have been converted to constant 1997 US\$, using a new and comprehensive dataset of industry-specific Purchasing Power Parities (PPPs). In the EU KLEMS project these PPP series were constructed by double deflation of gross output and intermediate inputs within a consistent input-output framework. Energy data consist of expenditure-based intermediate inputs that encompass all energy mining products, oil refining products and electricity and gas products. Using detailed supply-and-use tables, energy expenditures at the sector-level have been deflated in the EU KLEMS project by the relative price index of each fuel (energy carrier). Finally, because these intermediate energy input series are provided in volume indices, Mulder and De Groot (2012) have matched these with final energy consumption data provided by the International Energy Agency (IEA), to obtain energy consumption in kilo tonnes of oil equivalent (ktoe). The latter allows us to not only assess energy intensity growth rates, but also energy intensity levels across countries and subsectors.

To analyze the role of ICT in driving energy intensity trends in the services sector (see Section 5), we make use of EU KLEMS information on ICT capital services per hour worked, in constant US\$. It has been derived from the share of ICT assets in total asset compensation, based on agreed procedures concerning capital compensation including imputation for negative rentals. Furthermore, we control in our analysis for the impact of energy prices as well as heating and cooling days. Energy prices are sectorspecific and defined as expenditures on intermediate energy inputs per ktoe, in constant 1997 US\$. Data about heating and cooling degree days originate from the World Resources Institute (WRI). 


\section{Trends}

\section{Evolution of energy intensity over time}

Figure 1 shows for the various (clusters of) countries the evolution over time of energy intensity levels in the aggregate service sector. From the figure it can be seen that the dominant pattern (in the USA, OECD9, EU6, OECD18) is a very modest decrease in energy intensity levels, especially since the 1990s, with a temporary modest increase in energy intensity levels during approximately the period 1996-2003. A clear exception to this pattern is the service sector in Japan, which is characterized by a persistent and considerable increase in energy intensity since the first half of the 1980s. Also, the group of four new EU member states (former Eastern Europe) is somewhat special in that they exhibit a relatively strong decrease in energy intensity between 1995-2005, presumably because of a catching-up effect following their turn to market economies (Markandya et al. 2006, Mulder and De Groot 2012).

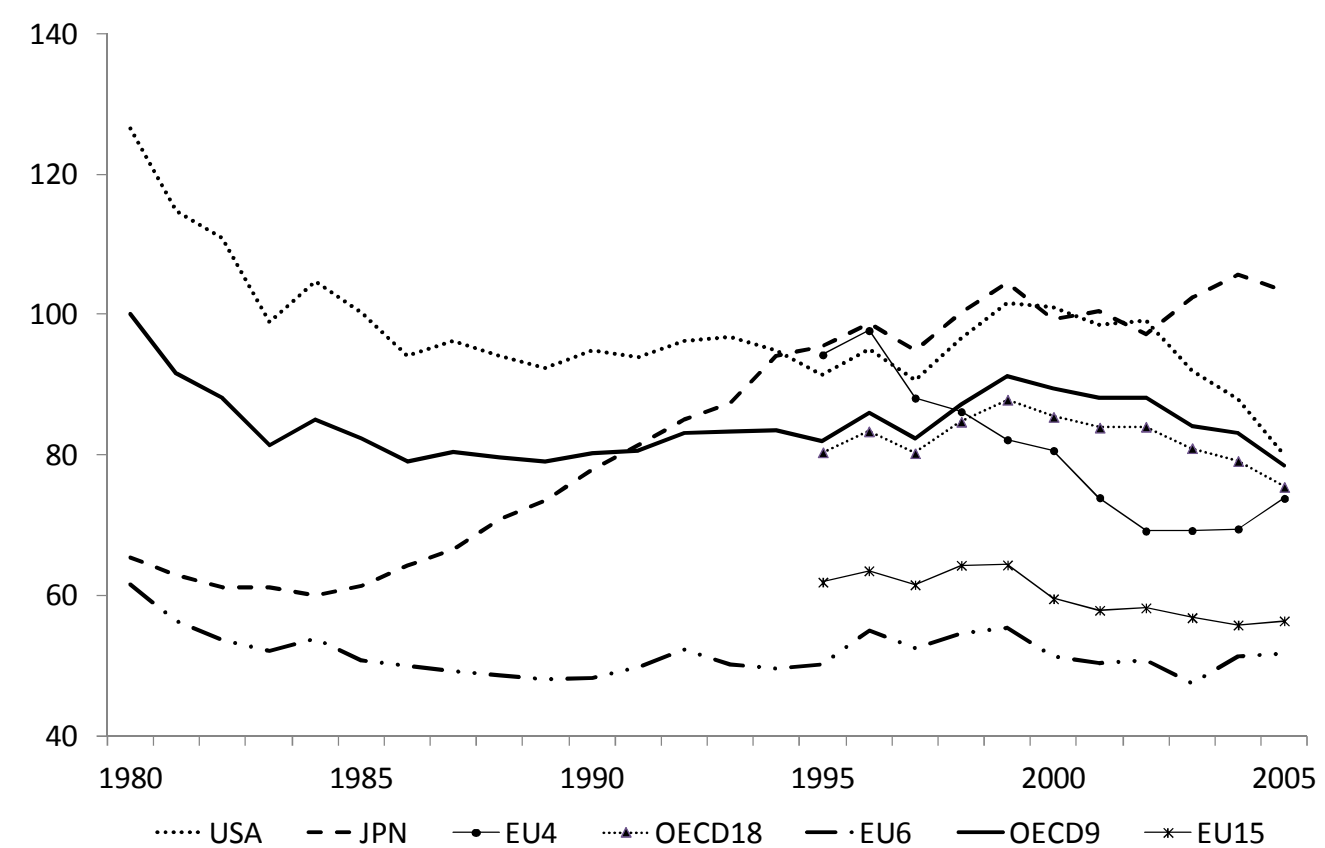

Figure 1. Energy intensity levels; index, relative to OECD9 in 1980 (OECD9 in 1980=100).

From Table 5 it can be seen that countries as diverse as Austria, Belgium, Finland, Japan, South Korea, the Netherlands, Spain and the UK exhibit positive growth rates of energy intensity in their service sector (i.e., increasing levels of energy intensity). This result is in sharp contrast with the aggregate economy level and the manufacturing sector, where most countries exhibit negative energy intensity growth rates and thus a decreasing energy-activity ratio (Mulder and De Groot 2012). Table 5 leads to a couple of observations. First, in the service sector changes in energy intensity levels differ substantially across countries, varying from an average annual increase of 3.0\% in Austria to an average annual decrease of $3.6 \%$ in Denmark, measured over the period 1980-2005. Across all periods these cross-country 
differences are considerably larger than in Manufacturing (cf. Mulder and De Groot 2012). Second, in contrast to manufacturing, in a range of countries growth in value added does not keep up with growth in energy use, resulting in increasing energy intensity levels in services. This trend is particularly strong in Austria, Finland and Japan, but also present in Spain and the United Kingdom. Third, in virtually all countries aggregate energy use in services increased over the past several decades, except for Denmark and after 1995 also for Hungary and Slovakia. 
Table 5. Change in energy use, value added and energy intensity at the aggregate Services level; average annual growth rates

\begin{tabular}{|c|c|c|c|c|c|c|c|c|c|}
\hline \multirow[t]{3}{*}{ growth rate } & \multicolumn{3}{|c|}{ Energy Intensity } & \multicolumn{3}{|c|}{ Energy Use } & \multicolumn{3}{|c|}{ Value Added } \\
\hline & 1980 & 1980 & 1995 & 1980 & 1980 & 1995 & 1980 & 1980 & 1995 \\
\hline & -2005 & -1995 & -2005 & -2005 & -1995 & -2005 & -2005 & -1995 & -2005 \\
\hline Austria & 3.0 & 3.4 & 2.4 & 5.3 & 5.9 & 4.4 & 2.2 & 2.4 & 1.9 \\
\hline Belgium & 0.8 & 2.9 & -2.5 & 2.6 & 4.6 & -0.3 & 1.9 & 1.6 & 2.3 \\
\hline Czech Republic & - & - & 1.8 & - & - & 3.4 & - & - & 1.6 \\
\hline Denmark & -3.6 & -3.1 & -4.3 & -1.3 & -1.0 & -1.8 & 2.3 & 2.1 & 2.5 \\
\hline Finland & 1.5 & 1.7 & 1.3 & 3.6 & 3.2 & 4.1 & 2.0 & 1.5 & 2.8 \\
\hline France & -1.7 & -2.7 & -0.3 & 0.5 & -0.4 & 1.7 & 2.2 & 2.4 & 2.0 \\
\hline Germany & -2.5 & -3.1 & -1.6 & -0.3 & -0.3 & -0.1 & 2.3 & 2.8 & 1.5 \\
\hline Hungary & - & - & -6.6 & - & - & -2.6 & - & - & 4.0 \\
\hline Japan & 1.8 & 2.5 & 0.8 & 4.9 & 6.3 & 2.8 & 3.0 & 3.7 & 1.9 \\
\hline Korea & 0.4 & -2.4 & 4.4 & 6.3 & 5.0 & 8.4 & 5.9 & 7.5 & 3.7 \\
\hline The Netherlands* & 0.4 & 1.7 & -1.4 & - & - & 1.6 & 2.7 & 1.2 & 3.1 \\
\hline Poland & - & - & 0.2 & - & - & 4.1 & - & - & 4.0 \\
\hline Portugal & -2.2 & -2.9 & -1.1 & 0.9 & 0.5 & 1.6 & 3.2 & 3.5 & 2.7 \\
\hline Spain & 0.9 & -2.1 & 5.5 & 4.0 & 0.4 & 9.7 & 3.1 & 2.6 & 3.9 \\
\hline Slovakia & - & - & -5.7 & - & - & -2.6 & - & - & 3.2 \\
\hline Sweden & - & - & -3.1 & - & - & -0.2 & - & - & 3.0 \\
\hline United Kingdom & 1.0 & 1.6 & 0.1 & 4.1 & 4.1 & 4.2 & 3.1 & 2.5 & 4.1 \\
\hline USA & -1.8 & -2.2 & -1.3 & 1.3 & 0.8 & 2.1 & 3.2 & 3.0 & 3.5 \\
\hline OECD9 & -0.7 & -1.3 & -0.4 & 2.1 & 1.7 & 2.7 & 3.1 & 3.0 & 3.1 \\
\hline EU6 & -0.7 & -1.4 & 0.3 & 2.0 & 1.0 & 3.4 & 2.7 & 2.4 & 3.1 \\
\hline OECD18 & - & - & -0.6 & - & - & 2.3 & - & - & 2.9 \\
\hline EU15 & - & - & -0.9 & - & - & 1.7 & - & - & 2.7 \\
\hline EU4 & - & - & -2.4 & - & - & 1.0 & - & - & 3.5 \\
\hline
\end{tabular}

Note: * Initial year 1987 instead of 1980, due to limited data availability. 


\section{Hypothetical development of energy intensity under various scenarios}

Next, we take a closer look at the impact that the observed energy intensity dynamics in the service sector have for the energy intensity development of the total economy. To this aim we present in Figure 2, for four (key groups of) countries, three hypothetical development paths of energy intensity at the aggregate economy level under different assumptions regarding (i) the share of the service sector, and (ii) energy efficiency development in the service sector.
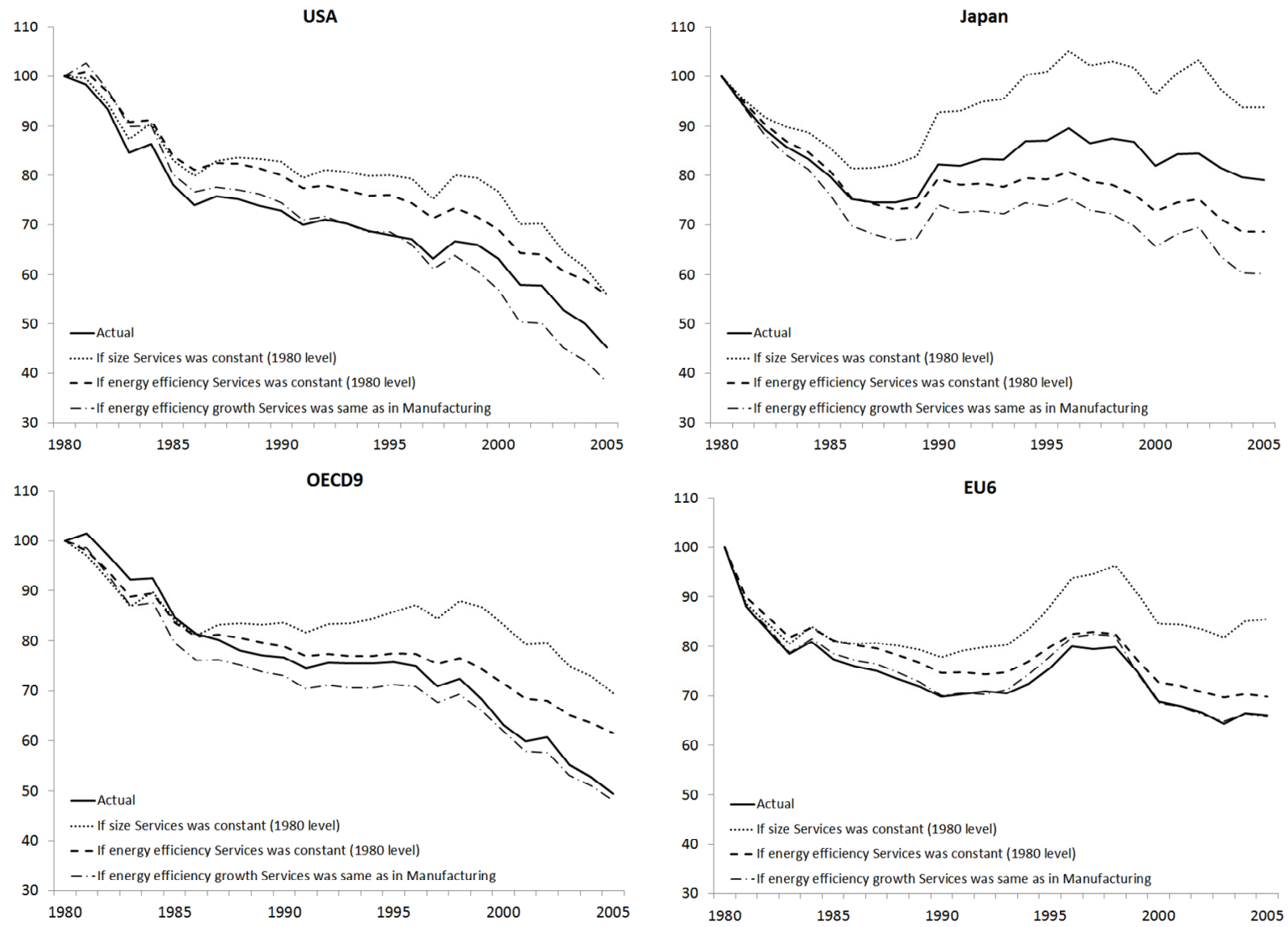

Figure 2. Aggregate (Total Economy) energy intensity trends under various scenarios

The bold line in the figure shows the actual (observed) total energy intensity level of the respective economies. As noted before (Table 2), it can be seen that energy intensity at the aggregate economy level has gradually decreased over time, especially in the USA and (thus) the OECD9 sample. The first of the remaining three hypothetical energy intensity lines shows the evolution of energy intensity levels in case the service sector would not have grown in size (measured in terms of value added) since 1980. The figure clearly shows that in all four country samples this would have led to a considerable higher overall level of energy intensity than the actual (observed) energy intensity level. Hence, the emergence of the service economy has substantially contributed to decreasing aggregate energy intensity levels in Western 
economies. Hence, our data lend support to the idea that the sectoral transition from manufacturing towards services helps alleviating environmental and security concerns related to the use of energy. Obviously, this is due to the fact that the service sector is relatively energy extensive as compared to other sectors, most notably manufacturing and transport.

The second hypothetical line in Figure 5 shows what the evolution of overall energy intensity levels would have been in case the service sector would not have improved its energy efficiency since 1980 . The figure clearly shows that, except for Japan, the assumption of no efficiency improvements in services would have led to higher overall energy intensity levels, but not as high as in the hypothetical case in which the service sector would not have grown beyond its 1980 size. This means that, except for Japan that features negative efficiency changes in the service sector, the rise of the service economy came along with a positive efficiency effect that contributed to a decrease in overall energy intensity levels. At the same time, the figure reveals that this efficiency effect was considerably smaller than the aforementioned structural effect. This insight is underlined by the third hypothetical line in Figure 2, which shows the evolution of overall energy intensity in case the service sector would have realized the same energy efficiency improvements as the manufacturing sector. It can be seen that across all samples this would have led to a lower overall energy intensity level than we actually observe, especially in the USA and Japan. This of course raises the question as to why energy efficiency improvements in the service sector have been relatively so modest. We return to this question in Sections 4 and 5.

\section{Relative positions of countries}

Figure 3 ranks countries according to their relative energy intensity performance in the aggregate service sector in 1995 and 2005. It can be seen that EU15 member states lead this ranking, while Japan, South Korea and former Eastern European countries are to be found at the bottom of this ranking. As regards these latter countries, it is to be noted that the relative performance of Japan and South Korea has deteriorated over time, while the opposite is true for Slovakia, Czech Republic and especially Hungary; also Poland is an exception, with a relatively low energy intensity level (top-5). 


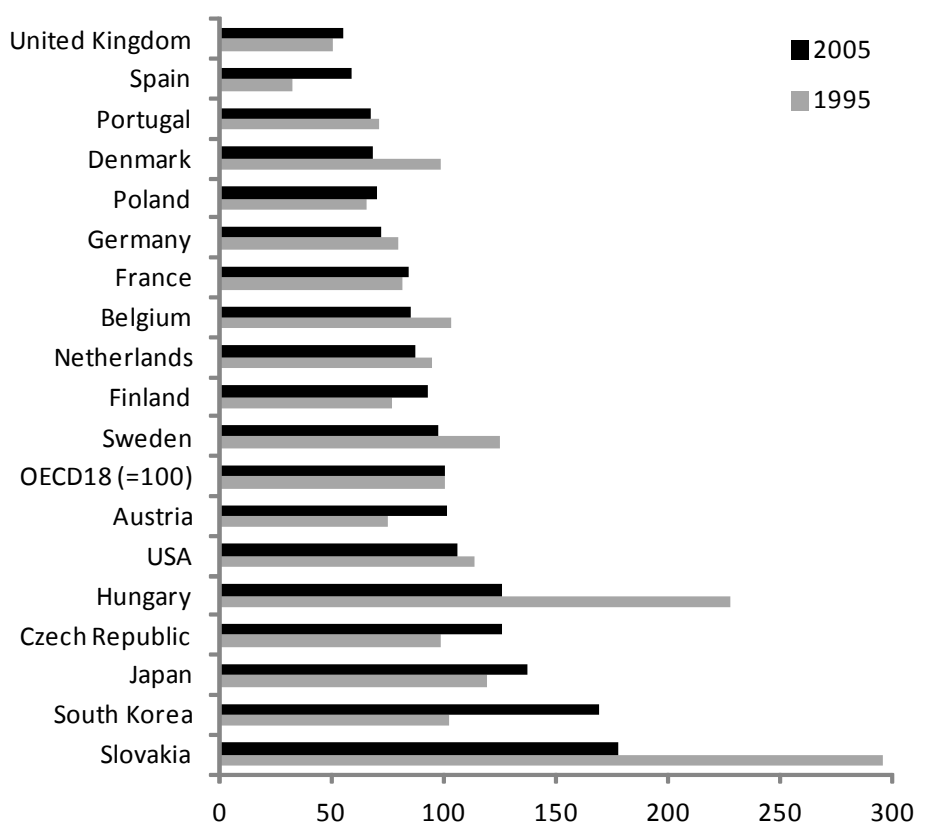

Figure 3. Energy intensity levels (Indexed; OECD18=100)

\section{Dynamics of the service sector}

Table 6 shows the evolution of the relative weight of the various subsectors in the total service sector over time, again both in terms of value added and energy consumption. It can be seen that in terms of energy consumption Wholesale and Retail Trade stands out as the dominant sector, although its relative weight has decreased considerably over time. In 2005 it was responsible for about one-third of all energy consumption in the service sector. In addition, the sectors Renting/Computer/R\&D, Public Administration, Health and Social Work and Other Services each account for about $10 \%$ of total energy consumption in the Service sector; the remaining $30 \%$ is consumed by all other sectors. By and large, this pattern is alike in terms of value added, except for the sectors Financial Intermediation and Education, which pair a relatively small energy share to a relatively high value added share. Of course, this implies that these sectors exhibit relatively low levels of energy intensity (see also Figure 4). 
Table 6. Shares service subsectors in total service sector - weighted average across countries

\begin{tabular}{|c|c|c|c|c|c|c|}
\hline & \multicolumn{3}{|c|}{ Value added (in \%) } & \multicolumn{3}{|c|}{ Energy (in \%) } \\
\hline & 1980 & 1995 & 2005 & 1980 & 1995 & 2005 \\
\hline Wholesale and retail trade & 17 & 20 & 20 & 41 & 35 & 32 \\
\hline Hotels and restaurants & 5 & 3 & 3 & 8 & 9 & 9 \\
\hline Post and telecommunications & 3 & 4 & 6 & 1 & 3 & 4 \\
\hline Financial intermediation & 9 & 10 & 11 & 3 & 4 & 4 \\
\hline Renting, computer, $\mathrm{R} \& \mathrm{D}$, other business & 10 & 11 & 13 & 10 & 9 & 10 \\
\hline Public administration and defence, compulsory social security & 19 & 16 & 13 & 13 & 14 & 13 \\
\hline Education & 15 & 14 & 12 & 5 & 5 & 6 \\
\hline Health and social work & 16 & 15 & 15 & 8 & 10 & 11 \\
\hline Other community, social and personal services & 6 & 7 & 6 & 9 & 10 & 11 \\
\hline
\end{tabular}

Figure 4 ranks the various service sectors in terms of their relative energy intensity levels. It can be seen that relatively low levels of energy intensity are to be found in Education and sectors that deal with Financial Intermediation activities. Relatively high energy intensity levels within the service sector are to be found in the sectors Sewage and Refuse Disposal, Hotels and Restaurants and Automobile Retail. Overall, the highest relative decreases in relative energy intensity performance have been realized in the various Retail sectors.

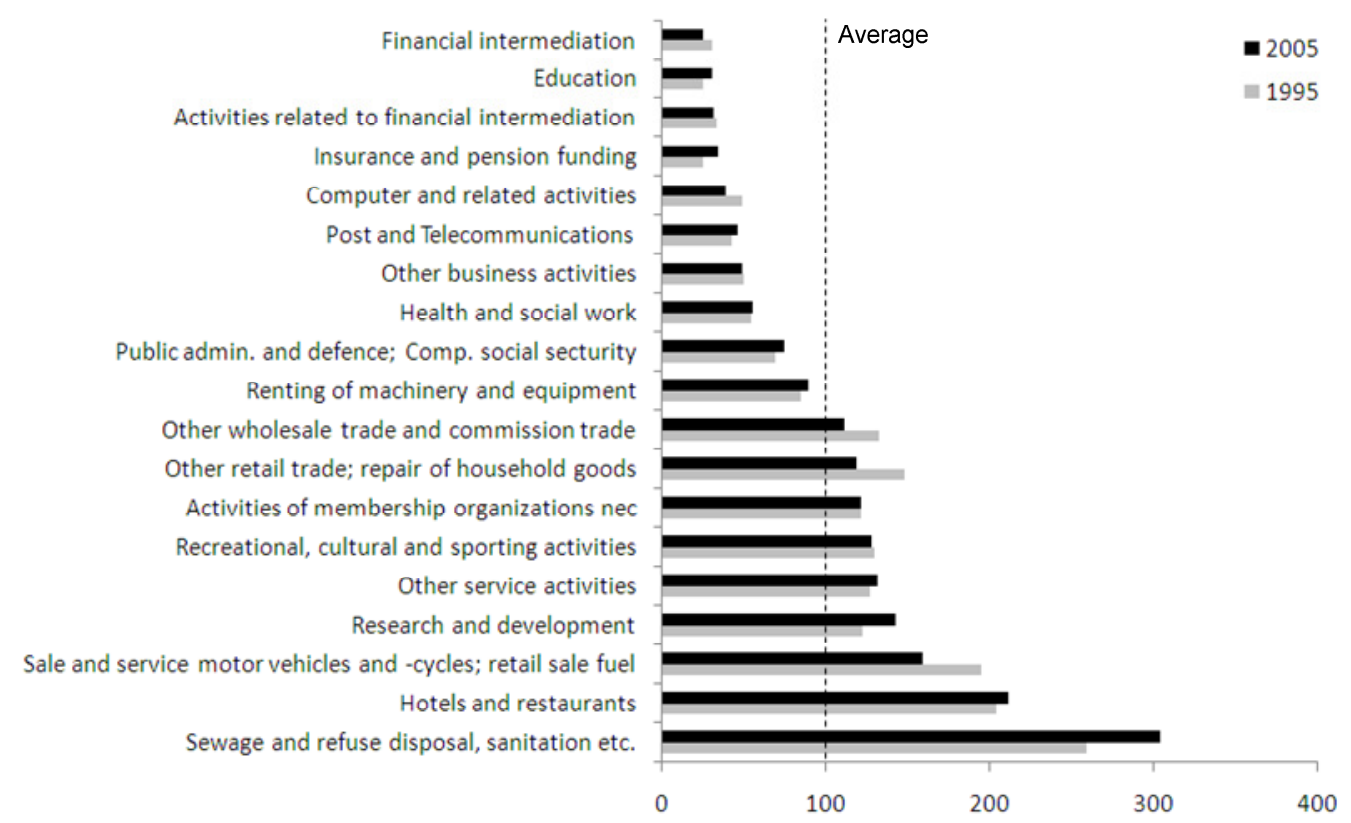

Figure 4. Relative energy intensity levels services sectors, average across all 18 countries (Indexed, average =100). 
In Table 7 we translate the observed changes in aggregate energy intensity in the service sector (Table 5) into annualized growth rates for the 23 underlying subsectors, for the periods 1980-1995 and 1995-2005. For the aggregate service sector, the table shows that between 1980 and 2005 energy intensity decreased on average with $1.8 \%$ per year in the USA, $0.7 \%$ in the OECD9 and EU6 regions; after 1995 the pace of change slowed down to $1.3 \%$ in the USA and $0.7 \%$ in the OECD9 region, while the trend reversed in the EU6 region with $0.3 \%$ annual increase. In contrast, in Japan aggregate energy intensity in services increased, on average with $1.8 \%$ per year between 1980 and 2005 and $0.8 \%$ between 1995 and 2005. In the EU4 region energy intensity decreased with an average of 2.4\% per year between 1995 and 2005.

In contrast to the aggregate economy and the manufacturing sector (see Mulder and De Groot 2012), underlying data reveal a slowdown of energy intensity decreases after 1995. In the USA most subsectors exhibit negative growth rates of energy intensity, especially in the trade and non-commercial service sectors. In Japan and the EU the picture is more diverse. In Japan especially the non-commercial service sectors exhibit relatively large positive growth rates of energy intensity. We refer to the Appendix for a listing of growth rates for individual service sectors per country, differentiated for the periods 1980-2005, 1980-1995 and 1995-2005. 
Table 7. Energy intensity growth rates by service subsector.

SERVICES

\section{WHOLESALE AND RETAIL TRADE}

Sale and repair motor vehicles and -cycles; retail sale of fuel

Other wholesale trade and commission trade

Other Retail trade; repair of household goods

HOTELS AND RESTAURANTS

\section{POST AND TELECOMMUNICATIONS}

FINANCIAL INTERMEDIATION

Financial intermediation, except insurance and pension funding

Insurance and pension funding, except comp. social security

Activities related to financial intermediation

RENTING, COMPUTER, R\&D and OTHER BUSINESS

Renting of machinery and equipment

Computer and related activities

Research and development

Other business activities

PUBLIC ADMIN. AND DEFENCE; COMP. SOCIAL SECURITY EDUCATION

HEALTH AND SOCIAL WORK

OTHER COMMUNITY, SOCIAL AND PERSONAL SERVICES

Sewage and refuse disposal, sanitation and similar activities

Activities of membership organizations n.e.c.

Recreational, cultural and sporting activities

Other service activities

\begin{tabular}{|c|c|c|c|c|c|c|c|c|c|c|}
\hline \multicolumn{2}{|c|}{ USA } & \multicolumn{2}{|c|}{ JPN } & \multicolumn{2}{|c|}{ OECD9 } & \multicolumn{2}{|c|}{ EU6 } & \multirow{2}{*}{$\begin{array}{r}\text { OECD18 } \\
1995\end{array}$} & \multirow{2}{*}{$\begin{array}{r}\text { EU15 } \\
1995\end{array}$} & \multirow{2}{*}{$\begin{array}{r}\text { EU4 } \\
1995\end{array}$} \\
\hline 1980 & 1995 & 1980 & 1995 & 1980 & 1995 & 1980 & 1995 & & & \\
\hline-2005 & -2005 & -2005 & -2005 & -2005 & -2005 & -2005 & -2005 & -2005 & -2005 & -2005 \\
\hline-1.8 & -1.3 & 1.8 & 0.8 & -0.7 & -0.4 & -0.7 & 0.3 & -0.6 & -0.9 & -2.4 \\
\hline-3.8 & -2.9 & 0.0 & -0.8 & -2.9 & -1.7 & -1.4 & 0.4 & -1.9 & -1.5 & -5.3 \\
\hline-4.6 & -5.1 & 5.0 & -0.2 & -2.3 & -2.7 & -0.2 & 1.2 & -2.1 & 0.6 & 1.0 \\
\hline-4.3 & -1.5 & -1.9 & 0.3 & -3.5 & -0.8 & -2.0 & -0.3 & -1.8 & -3.3 & -8.2 \\
\hline-3.2 & -4.2 & 1.8 & -0.5 & -2.2 & -2.5 & -1.1 & 1.0 & -2.2 & -0.1 & -4.6 \\
\hline-0.3 & -1.1 & 3.5 & 4.1 & 0.5 & 0.4 & 1.0 & 1.1 & 0.3 & -0.2 & -2.1 \\
\hline-2.6 & -3.3 & 1.5 & 4.2 & 2.5 & 1.7 & -1.3 & -2.9 & 0.7 & -3.7 & -9.7 \\
\hline-1.3 & -1.7 & -1.3 & 0.0 & -1.0 & -1.2 & -0.3 & -1.8 & -0.8 & -0.3 & 0.4 \\
\hline-2.6 & -2.8 & -1.5 & -0.9 & -1.8 & -2.2 & -1.1 & -3.6 & -2.1 & -2.4 & -3.5 \\
\hline 1.0 & 1.0 & -0.6 & 2.3 & 5.0 & 1.9 & 3.8 & 1.0 & 3.0 & 6.4 & 10.1 \\
\hline - & - & - & - & -1.4 & -1.4 & -1.2 & -1.9 & -0.5 & -0.7 & -11.7 \\
\hline-1.4 & 0.4 & 1.0 & -1.3 & -1.2 & -0.2 & -2.5 & -2.0 & -0.3 & -1.7 & -6.8 \\
\hline 2.7 & 3.6 & -13.1 & -18.8 & 2.1 & 0.8 & 4.4 & 1.0 & 0.5 & -0.9 & -1.5 \\
\hline-3.2 & -1.4 & 3.1 & -1.1 & -1.5 & -2.5 & -2.3 & -2.7 & -2.6 & -2.9 & -2.8 \\
\hline-1.9 & 2.0 & 2.5 & 3.9 & -0.5 & 2.6 & -0.2 & 3.0 & 1.4 & -0.7 & 0.5 \\
\hline-1.8 & 0.2 & 2.2 & 0.9 & -1.8 & -0.2 & -3.4 & -2.5 & -0.2 & -1.5 & -7.8 \\
\hline 0.8 & 0.9 & 3.0 & -0.6 & 1.2 & 0.7 & 0.6 & 1.6 & 0.7 & 0.8 & -0.3 \\
\hline-0.9 & 1.0 & 3.8 & 3.4 & 1.1 & 2.9 & 0.8 & 3.9 & 1.8 & 1.5 & 2.5 \\
\hline-0.3 & -1.0 & 2.4 & 0.6 & 1.1 & 1.2 & 0.2 & 1.5 & 0.2 & -1.9 & 0.5 \\
\hline-2.5 & -0.9 & 3.4 & 1.6 & -0.9 & -0.1 & -0.8 & -0.3 & 0.1 & 0.2 & 2.3 \\
\hline 1.0 & 0.8 & 9.0 & 2.1 & 0.3 & -0.1 & -1.8 & 0.0 & 1.5 & 3.0 & 3.3 \\
\hline-2.8 & -0.3 & -0.3 & -0.5 & -2.1 & 0.0 & -0.3 & 1.6 & 0.0 & -0.1 & -1.4 \\
\hline-2.1 & -1.1 & 4.1 & 1.2 & 0.1 & -0.3 & -1.1 & -0.9 & -0.2 & -0.6 & -0.1 \\
\hline-3.2 & -1.7 & 1.6 & 2.1 & -1.1 & 0.0 & 1.8 & -0.4 & 0.3 & -0.5 & 2.4 \\
\hline
\end{tabular}




\section{Sigma convergence}

We conclude this section with a brief analysis of the evolution of cross-countries differences in energy intensity levels over time for the main service sectors. This analysis builds on recent work on crosscountry convergence of energy- or emission intensities (see, for example, Aldy 2006, Markandya et al. 2006, Liddle 2009, Miketa and Mulder 2005, Mulder and De Groot 2007, and Romero-Avila 2008). Convergence can be understood both in terms of levels and growth rates, which translates into a distinction between so-called $\sigma$-convergence and $\beta$-convergence (e.g., Barro 1991, Barro and Sala-iMartin 1992). The former refers to a decreasing variance of cross-country differences in productivity or intensity levels, while the latter refers to a tendency of countries with relatively high (low) initial intensity (productivity) levels to grow relatively fast, building upon the proposition that growth rates tend to decline as countries approach their steady state (see Section 5). ${ }^{4}$

To measure cross-country differences in energy intensity we calculate for each sector the unweighted cross-country standard deviation of the log of energy intensity over time. Decreasing variance in energy intensity levels among countries is then taken as evidence for $\sigma$-convergence. Our analysis comprises the aggregate service sector and nine service subsectors (at 2-digit level). The results are depicted in Figure 5. The figure shows that, in general, in the service sector cross-country variation in energy intensity levels has decreased over time, indicating $\sigma$-convergence. When measured at the aggregate service sector level (top-left graph), the cross-country variance decreases relatively rapid until 1995. For the OECD9 sample it tends to stagnate between 1995 and 2003. As regards the subsectors, the figure reveals that by 2005 the highest degree of cross-country variation in energy intensity is to be found in the sectors Post and Telecommunication, whereas cross-country differences in energy intensity levels are relatively small in the sectors Wholesale and Retail Trade, Renting etc., Public Administration and Defense, and Education. Moreover, the figure shows that in most subsectors cross-country variation in energy intensity levels has decreased over time. This pattern of $\sigma$-convergence is particularly strong in the subsectors Wholesale and Retail Trade, Public Administration and Education. In contrast, there is evidence of $\sigma$-divergence in the sectors Hotels and Restaurants, Post and Telecommunication, Financial Intermediation, and Health and Social Work. In the sector Other Social Services cross-country variation in energy intensity levels remains more or less constant over time. In Table 8 we summarize these trends in percentage changes.

\footnotetext{
${ }^{4}$ Note that $\beta$-convergence is a necessary but not a sufficient condition for $\sigma$-convergence to occur (cf. Galton's fallacy; see Quah 1993), implying that in cases where we find evidence for $\sigma$-convergence, we know for sure that $\beta$ convergence is also present.
} 

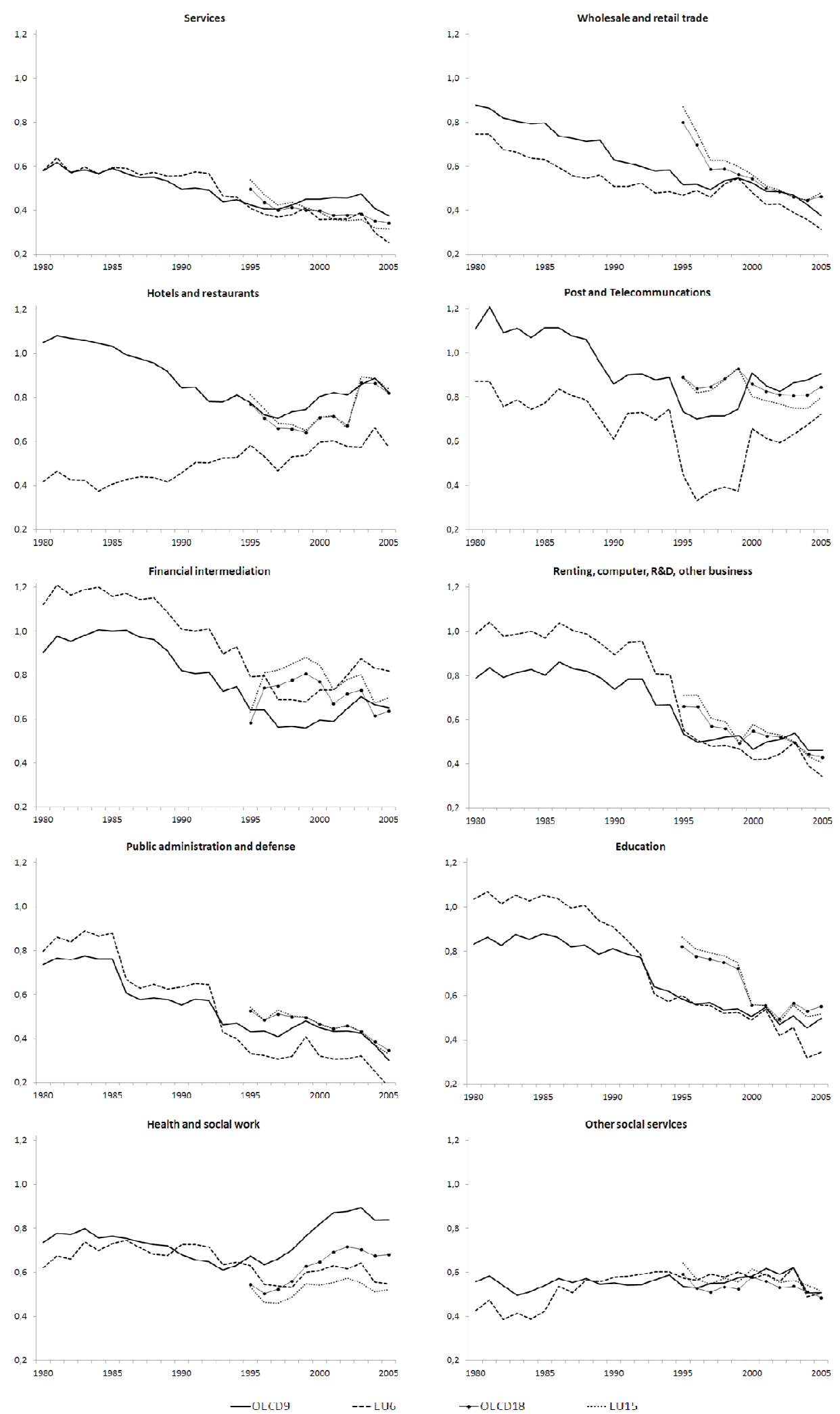

Figure 5. $\sigma$-convergence analysis, measured as standard deviation of log(energy intensity) 
Table 8. Percentage change of $\sigma$ in different time-periods and for different country groupings

SERVICES

\section{WHOLESALE AND RETAIL TRADE}

Sale and repair motor vehicles and -cycles; retail sale of fuel

Other wholesale trade and commission trade

Other Retail trade; repair of household goods

HOTELS AND RESTAURANTS

POST AND TELECOMMUNICATIONS

FINANCIAL INTERMEDIATION

Financial intermediation, except insurance and pension funding

Insurance and pension funding, except comp. social security

Activities related to financial intermediation

RENTING, COMPUTER, R\&D and OTHER BUSINESS

Renting of machinery and equipment

Computer and related activities

Research and development

Other business activities

PUBLIC ADMIN. AND DEFENCE; COMP. SOCIAL SECURITY EDUCATION

HEALTH AND SOCIAL WORK

OTHER COMMUNITY, SOCIAL AND PERSONAL SERVICES

Sewage and refuse disposal, sanitation and similar activities

Activities of membership organizations n.e.c.

Recreational, cultural and sporting activities

Other service activities

\begin{tabular}{|c|c|c|c|c|c|c|c|c|}
\hline \multicolumn{3}{|c|}{ OECD9 } & \multicolumn{3}{|c|}{ EU6 } & \multirow{2}{*}{$\begin{array}{r}\text { OECD18 } \\
1995- \\
2005 \\
\end{array}$} & \multirow{2}{*}{$\begin{array}{r}\text { EU15 } \\
1995- \\
2005 \\
\end{array}$} & \multirow{2}{*}{$\begin{array}{r}\text { EU4 } \\
1995- \\
2005 \\
\end{array}$} \\
\hline $\begin{array}{r}1980- \\
2005 \\
\end{array}$ & $\begin{array}{r}1980- \\
1995 \\
\end{array}$ & $\begin{array}{r}1995- \\
2005 \\
\end{array}$ & $\begin{array}{r}1980- \\
2005 \\
\end{array}$ & $\begin{array}{r}1980- \\
1995 \\
\end{array}$ & $\begin{array}{r}1995- \\
2005 \\
\end{array}$ & & & \\
\hline-0.35 & -0.27 & -0.11 & -0.57 & -0.30 & -0.38 & -0.31 & -0.42 & -0.46 \\
\hline-0.57 & -0.41 & -0.27 & -0.58 & -0.37 & -0.33 & -0.42 & -0.45 & -0.46 \\
\hline-0.56 & -0.36 & -0.32 & -0.43 & 0.21 & -0.53 & 0.01 & 0.08 & 0.13 \\
\hline-0.41 & -0.40 & -0.02 & -0.40 & -0.37 & -0.05 & -0.37 & -0.40 & -0.61 \\
\hline-0.56 & -0.32 & -0.36 & -0.73 & -0.39 & -0.55 & -0.44 & -0.49 & -0.44 \\
\hline-0.22 & -0.26 & 0.06 & 0.38 & 0.40 & -0.02 & 0.06 & 0.03 & 0.50 \\
\hline-0.18 & -0.34 & 0.23 & -0.17 & -0.48 & 0.61 & -0.05 & -0.10 & -0.24 \\
\hline-0.28 & -0.29 & 0.02 & -0.27 & -0.29 & 0.03 & 0.09 & 0.10 & -0.73 \\
\hline-0.12 & -0.24 & 0.16 & -0.05 & -0.20 & 0.19 & 0.04 & 0.05 & -0.65 \\
\hline-0.56 & -0.60 & 0.12 & -0.56 & -0.61 & 0.13 & 0.15 & 0.13 & 0.04 \\
\hline-0.42 & -0.32 & -0.14 & -0.65 & -0.44 & -0.38 & -0.35 & -0.43 & -0.51 \\
\hline-0.04 & -0.37 & 0.52 & -0.57 & -0.36 & -0.33 & 0.18 & -0.23 & -0.39 \\
\hline-0.02 & -0.12 & 0.10 & -0.41 & -0.27 & -0.20 & -0.01 & -0.11 & -0.38 \\
\hline 0.24 & 0.39 & -0.11 & -0.01 & 0.33 & -0.26 & -0.18 & -0.25 & -0.48 \\
\hline-0.48 & -0.39 & -0.16 & -0.59 & -0.44 & -0.27 & -0.50 & -0.55 & -0.66 \\
\hline-0.59 & -0.42 & -0.30 & -0.78 & -0.58 & -0.46 & -0.34 & -0.39 & -0.43 \\
\hline-0.40 & -0.30 & -0.15 & -0.67 & -0.42 & -0.43 & -0.33 & -0.40 & -0.49 \\
\hline 0.14 & -0.08 & 0.24 & -0.12 & 0.01 & -0.13 & 0.25 & -0.02 & 0.31 \\
\hline-0.09 & -0.04 & -0.05 & 0.19 & 0.35 & -0.12 & -0.18 & -0.20 & -0.59 \\
\hline-0.41 & -0.52 & 0.23 & -0.20 & -0.55 & 0.80 & 0.04 & 0.09 & -0.15 \\
\hline-0.03 & -0.16 & 0.15 & 0.38 & 0.12 & 0.22 & -0.02 & -0.03 & -0.79 \\
\hline-0.01 & 0.03 & -0.04 & -0.10 & 0.09 & -0.17 & -0.17 & -0.22 & -0.34 \\
\hline-0.40 & -0.12 & -0.32 & -0.50 & 0.31 & -0.62 & -0.35 & -0.47 & -0.48 \\
\hline
\end{tabular}




\section{Decomposition analysis}

Changes in energy intensity at the aggregate service level result not only from energy efficiency improvements in individual service sectors (the so-called efficiency effect), but also from changes in the composition of the service sector (the structural effect). The efficiency effect is supposedly largely driven by energy-saving technology adoption while the structural effect is caused by the fact that some sectors are more energy intensive (e.g. sewage and refuse disposal) than others (e.g. financial intermediation). By using index number decomposition (or shift-share) analysis, we can identify the role of these two effects in driving aggregate energy intensity changes in the service sector. In the field of energy studies this methodology has been widely used to decompose aggregate changes in energy use, energy intensity, or emission intensity (see Ang and Zhang 2000 and Liu and Ang 2007 for reviews). To describe the essence of index number decomposition methodology algebraically, let $i$ denote the sectors of the economy and let $Y$ and $E$ represent output (value added) and energy consumption. Aggregate energy intensity $I$ in the service sector defined as the ratio of energy to output in the aggregate service sector, can then be calculated as:

$$
I=\frac{E}{Y}=\sum_{i} \frac{E_{i}}{Y_{i}} \frac{Y_{i}}{Y}=\sum_{i} I_{i} S_{i}
$$

In this equation, $I_{i}$ represents the energy intensity of sub-sector $i ; S_{i}$ is the share of sub-sector $i$ in total value added. The efficiency effect can then be determined as a within-sector intensity effect, derived by controlling aggregate energy intensity for adjustments in the sectoral structure. Since both the structure effect and the efficiency effect change over time, one has to establish appropriate weights in order to measure the contribution of each effect. Decomposition analysis in the field of energy studies have used a variety of weights, which translates into a range of slightly different applied decomposition approaches (see Ang et al. 2003, Ang 2004, Ang et al. 2004, Boyd and Roop 2004, and Zhang and Ang 2001, for reviews and details). In this study we use the so-called log mean Divisia index method (LMDI I), as introduced by Ang and Liu (2001), which in its additive form decomposes a change in aggregate energy intensity $\left(\Delta I_{t o t}\right)$ between period 0 and $T$ into an efficiency effect $\left(\Delta I_{e f f}\right)$ and a structure effect $\left(\Delta I_{s t r}\right)$ according to:

$$
\begin{aligned}
& \Delta I_{e f f}=\sum_{i} w_{i} \ln \left(\frac{I_{i}^{T}}{I_{i}^{0}}\right), \\
& \Delta I_{s t r}=\sum_{i} w_{i} \ln \left(\frac{S_{i}^{T}}{S_{i}^{0}}\right),
\end{aligned}
$$


where $w_{i}$ is the weighting function defined as $w_{i}=L\left(V_{i}^{T}, V_{i}^{0}\right)$, with $V_{i}=\sum I_{i} S_{i}$ and $L$ the logarithmic average of two positive numbers $a$ and $b$ given by $L(a, b)=(a-b) / \ln (a / b) .^{5}$

In Table 9 we present the results of our decomposition analysis, for each country (group) and two time periods (1980-2005 and 1995-2005). We differentiate between the average annualized energy intensity growth rates before decomposition (gross) and after decomposition (net), i.e. after correcting for the impact of structural changes. Table 9 shows that in most countries energy intensity changes in the service sector have been influenced more by (technology-driven) efficiency improvements within sectors than by structural shifts in the composition of the service sector. Nevertheless, in some countries - most notably France, Japan, South Korea, Portugal and United Kingdom - these shifts are substantial, and in general the impact of structural effects on aggregate energy intensity has increased considerably after 1995.

\footnotetext{
${ }^{5}$ This choice is primarily motivated by the ability of LMDI to satisfy the factor-reversal test, i.e. it provides perfect decomposition results without a residual. Moreover, it can effectively handle zero values, the results are invariant to scaling, and it satisfies the time-reversal test, i.e. estimated values between period 0 and $T$ and period $T$ and 0 are equal (in absolute terms). In the two-factor case, LMDI is equivalent to the Fisher ideal index method, defined as the geometric average of the Laspeyres and Paasche indices (Ang 2004, Boyd and Roop 2004). For these reasons the LMDI and Fisher ideal index methods have emerged as the preferred methods in energy decomposition analysis (Ang 2004).
} 
Table 9. Decomposition of average annual growth rate of energy intensity in the service sector.

\begin{tabular}{|c|c|c|c|c|c|c|c|c|}
\hline & \multicolumn{4}{|c|}{ Average annual growth rate } & \multicolumn{4}{|c|}{$\%$ Contribution of Efficiency and Structure Effect } \\
\hline & \multicolumn{2}{|c|}{ 1980-2005 } & \multicolumn{2}{|c|}{ 1995-2005 } & \multicolumn{2}{|c|}{ 1980-2005 } & \multicolumn{2}{|c|}{ 1995-2005 } \\
\hline & Gross & Net & Gross & Net & $\begin{array}{l}\text { Efficiency } \\
\text { Effect }\end{array}$ & $\begin{array}{l}\text { Structure } \\
\text { Effect }\end{array}$ & $\begin{array}{l}\text { Efficiency } \\
\text { Effect }\end{array}$ & $\begin{array}{c}\text { Structure } \\
\text { Effect }\end{array}$ \\
\hline Austria & 3.0 & 3.1 & 2.4 & 2.4 & 103 & -3 & 100 & 0 \\
\hline Belgium & 0.8 & 0.9 & -2.5 & -2.3 & 119 & -19 & -91 & -9 \\
\hline Czech Republic & - & - & 1.8 & -0.1 & - & - & 21 & 79 \\
\hline Denmark & -3.6 & -3.5 & -4.3 & -3.9 & -100 & 0 & -86 & -14 \\
\hline Finland & 1.5 & 1.4 & 1.3 & 1.3 & 98 & 2 & 104 & -4 \\
\hline France & -1.7 & -1.9 & -0.3 & -0.4 & -779 & 879 & -278 & 178 \\
\hline Germany & -2.5 & -2.3 & -1.6 & -1.5 & -92 & -8 & -85 & -15 \\
\hline Hungary & - & - & -6.6 & -6.8 & - & - & -103 & 3 \\
\hline Italy & - & - & - & - & - & - & -98 & -2 \\
\hline Japan & 1.8 & 2.1 & 0.8 & 0.9 & 117 & -17 & 161 & -61 \\
\hline South Korea & 0.4 & -0.6 & 4.4 & 3.9 & -182 & 282 & 98 & 2 \\
\hline The Netherlands & 0.4 & 0.6 & -1.4 & -1.0 & 147 & -47 & -69 & -31 \\
\hline Poland & - & - & 0.2 & -0.2 & - & - & -368 & 468 \\
\hline Portugal & -2.2 & -1.6 & -1.1 & -0.5 & -71 & -29 & -32 & -68 \\
\hline Spain & 0.9 & 0.9 & 5.5 & 5.5 & 101 & -1 & 101 & -1 \\
\hline Slovakia & - & - & -5.7 & -6.4 & - & - & -112 & 12 \\
\hline Sweden & - & - & -3.1 & -2.7 & - & - & -87 & -13 \\
\hline United Kingdom & 1.0 & 1.1 & 0.1 & 0.5 & 105 & -5 & 460 & -360 \\
\hline USA & -1.8 & -2.1 & -1.3 & -1.3 & -115 & 15 & -110 & 10 \\
\hline OECD9 & -0.7 & -0.9 & -0.4 & -0.3 & -130 & 30 & -74 & -26 \\
\hline EU6 & -0.7 & -0.8 & 0.3 & 0.4 & -111 & 11 & 114 & -14 \\
\hline OECD18 & - & - & -0.6 & -0.5 & - & - & -78 & -22 \\
\hline EU15 & - & - & -1.0 & -0.9 & - & - & -86 & -14 \\
\hline EU4 & - & - & -2.6 & -3.2 & - & - & -127 & 27 \\
\hline
\end{tabular}

Most importantly, Table 9 shows that after controlling for structural changes in the service sector, in about one-third of the OECD countries in our sample, energy intensity levels increase over time. Even stronger, the results reveal that in various countries structural changes obscure a poor within-sector energy efficiency performance. For example, measured over the period 1980-2005, net energy intensity levels increase faster than gross energy intensity levels in Austria, Belgium, the Netherlands, Japan, and the United Kingdom. For the latter two countries this also holds for the period 1995-2005. In addition, measured over the period 1995-2005, in Belgium, Denmark, France, Germany, the Netherlands, Portugal, and Sweden the observed decrease in gross energy intensity levels slows down once we correct for the 
impact of structural changes in sector composition. For Denmark, Germany and Portugal this also holds for the period 1980-2005. In contrast, structural effects contribute to further energy intensity increases in the Czech Republic and South Korea (both after 1995), and slow down net energy intensity decreases in France, Hungary, Slovakia and (before 1995) the USA. Poland appears to be exceptional in that controlling for structural changes turns a positive gross energy intensity growth rate into a negative net energy intensity growth rate, i.e. into decreasing net energy intensity levels.

Together, these trends imply that, during the period 1995-2005, on average in the full sample of countries (OECD18), the observed $0.6 \%$ average annual decrease in observed gross energy intensity levels slows down to $0.5 \%$ per year, once we control for changes in the (sub-)sector composition of the service sector. For the aggregate OECD9 region, net energy intensity levels decrease between 1995 and 2005 on average with $0.3 \%$ per year, as compared to a $0.4 \%$ annual decrease of observed gross energy intensity levels. For the EU15 sample, the average annual decrease amounts to, respectively, $0.9 \%$ (net) and $1.0 \%$ (gross). In the group of Eastern European countries (EU4), these numbers are, respectively, $3.2 \%$ (net) and $2.6 \%$ (gross). In contrast, within the EU6 region, during the same period (1995-2005) net energy intensity levels increase on average with $0.4 \%$ per year, as compared to a $0.3 \%$ annual increase of observed gross energy intensity. During the whole period 1980-2005, the $0.7 \%$ average annual decrease of gross energy intensity levels at the OECD9 and EU6 samples, changes into, respectively, a $0.9 \%$ and $0.8 \%$ average annual reduction, once we correct for structural effects. These figures underline, once more, that especially after 1995, in many OECD countries the within-sector energy efficiency performance is worse than the observed gross energy intensity growth rates suggest - with a clear exception for Eastern European countries.

In order to examine the role of individual service subsectors in driving the aggregate results presented above, we identify for each individual subsector the percentage contribution of the total efficiency effect and the total structure effect to the aggregate service sector energy intensity growth rate. The results are presented in Tables 10a-c, again for the periods 1980-2005 and 1995-2005, and the same selection of (samples of) countries. The bottom line of the tables confirms that changes in aggregate service sector energy intensity result mainly from within-sector (technology-driven) efficiency changes, but that after 1995 and especially in Japan, the structure effects start to play a prominent role. Also, it confirms that in the USA, as well as in the EU6 and EU4 regions, structural changes contributed to increased energy intensity levels, whereas the opposite is true in Japan and the other regions.

The sectoral breakdown provided in Tables 10a-c shows that the efficiency effect is mainly realized within the various Wholesale and Retail sectors, as well as in Post and Telecommunication, Financial Intermediation and Other Business Activities. In Japan these achievements are undone by decreasing within-sector efficiency in the sectors Hotel and Restaurants, Public Administration and Defense, Education and Health and Social Work. Hence, these latter sectors predominantly drive the previously observed striking increase in aggregate service sector energy intensity in Japan. But also in some other regions within the OECD, Public Administration and Defense as well as Education feature considerable increases in within-sector energy intensity levels. It is also to be noted that the efficiency effect in the 
sectors Post and Telecommunication and Financial Intermediation differs substantially across the various countries and regions. As regards the structural effect, the sectoral breakdowns provided in Tables 10a-c show that, in general, energy intensity increases are especially driven by the emergence of the sectors Post and Telecommunications and Financial intermediation. In contrast, energy intensity levels have mainly decreased under influence of a shift towards the sectors Hotel and Restaurants, Public Administration and (to a lesser extent) Education. Furthermore, it is to be noted that the rise of the sector Retail and Trade had a considerable mixed impact on energy intensity trends, depending on the country and region. Finally, the substantial overall impact of structural changes on decreasing energy intensity in Japan appears to mainly caused by a shift towards the sectors Retail and Trade, Hotels and Restaurants, Public Administration and Education. We refer to the Appendix for more detailed country figures. 
Table 10a. Percentage contribution of the efficiency effect (EFF) and the structure effect (STR) by sector to the annual growth rate of service sector energy intensity (TOT) in the period 1980-2005. GDP-weighted cross-country averages.

\begin{tabular}{|c|c|c|c|c|c|c|c|c|c|c|c|c|}
\hline & \multicolumn{3}{|c|}{ USA } & \multicolumn{3}{|c|}{ Japan } & \multicolumn{3}{|c|}{ OECD9 } & \multicolumn{3}{|c|}{ EU6 } \\
\hline & $\mathrm{EFF}$ & STR & TOT & EFF & STR & TOT & $\mathrm{EFF}$ & STR & TOT & EFF & STR & TOT \\
\hline Sale, maintenance, repair motor vehicles and -cycles; retail sale of fuel & -22.8 & 12.2 & -10.6 & 1.8 & -0.5 & 1.3 & -23.5 & 6.4 & -17.1 & -1.4 & -11.6 & -13.0 \\
\hline Other wholesale trade and commission trade & -39.3 & 12.5 & -26.9 & -8.4 & 5.4 & -3.0 & -82.7 & 31.7 & -51.0 & -75.9 & 21.7 & -54.3 \\
\hline Other retail trade; repair of household goods & -31.1 & 4.7 & -26.4 & 12.1 & -10.2 & 1.9 & -50.1 & 8.2 & -41.9 & -22.6 & 4.5 & -18.1 \\
\hline Hotels and restaurants & -1.6 & -7.1 & -8.7 & 29.0 & -19.4 & 9.6 & 6.8 & -18.3 & -11.5 & 11.3 & -14.8 & -3.5 \\
\hline Post and Telecommunications & -2.6 & 1.3 & -1.4 & 3.5 & 7.4 & 11.0 & 6.9 & 7.0 & 13.9 & -6.8 & 19.9 & 13.1 \\
\hline Financial intermediation, except insurance and pension funding & -4.2 & 4.8 & 0.6 & -1.6 & 2.4 & 0.8 & -7.3 & 9.9 & 2.6 & -4.4 & 2.3 & -2.1 \\
\hline Insurance and pension funding, except compulsory social security & 0.3 & -0.8 & -0.4 & -0.4 & 0.3 & -0.1 & 6.1 & -6.5 & -0.4 & 27.7 & 2.8 & 30.4 \\
\hline Activities related to financial intermediation & 0.0 & 0.0 & 0.0 & 0.0 & 0.0 & 0.0 & -0.2 & 0.6 & 0.4 & -1.3 & 3.3 & 2.0 \\
\hline Renting of machinery and equipment & 2.9 & -1.3 & 1.7 & -3.9 & 4.0 & 0.1 & 5.0 & -0.2 & 4.8 & 8.4 & -4.5 & 3.9 \\
\hline Computer and related activities & -1.0 & 2.2 & 1.2 & 3.7 & -0.4 & 3.3 & -2.2 & 6.2 & 4.0 & -6.9 & 6.7 & -0.2 \\
\hline Other business activities & -6.7 & 2.1 & -4.6 & 3.7 & 2.7 & 6.3 & -16.8 & 11.3 & -5.5 & -50.9 & 30.6 & -20.3 \\
\hline Public administration and defence; Compulsory social security & 5.6 & -14.7 & -9.0 & 20.7 & -1.5 & 19.1 & 21.9 & -26.7 & -4.8 & 12.1 & -31.7 & -19.6 \\
\hline Education & -0.7 & -0.6 & -1.2 & 12.2 & -4.4 & 7.9 & 5.4 & -3.5 & 1.9 & 10.6 & -15.3 & -4.7 \\
\hline Health and social work & -0.9 & -2.1 & -3.0 & 19.9 & 2.5 & 22.5 & 13.4 & -1.4 & 12.0 & 3.1 & -5.7 & -2.6 \\
\hline Sewage and refuse disposal, sanitation and similar activities & 1.2 & -2.5 & -1.4 & 2.1 & -0.9 & 1.2 & 0.8 & -1.9 & -1.1 & -5.8 & 3.4 & -2.4 \\
\hline Activities of membership organizations n.e.c. & -6.1 & 1.8 & -4.4 & -0.1 & -0.8 & -0.9 & -9.1 & 2.3 & -6.8 & -0.6 & -0.9 & -1.5 \\
\hline Recreational, cultural and sporting activities & -3.1 & 2.3 & -0.8 & 16.3 & -5.0 & 11.3 & 0.6 & 3.9 & 4.5 & -9.3 & 3.8 & -5.5 \\
\hline Other service activities & -4.4 & -0.4 & -4.8 & 4.4 & -0.8 & 3.6 & -4.3 & -1.7 & -6.0 & 2.6 & -3.3 & -0.7 \\
\hline SERVICES & -115.3 & 15.3 & -100.0 & 117.4 & -17.4 & 100.0 & -130.0 & 30.0 & -100.0 & -110.5 & 10.5 & -100.0 \\
\hline
\end{tabular}


Table 10b. Percentage contribution of the efficiency effect (EFF) and the structure effect (STR) by sector to the annual growth rate of service sector energy intensity (TOT) in the period 1995-2005. GDP-weighted cross-country averages.

\begin{tabular}{|c|c|c|c|c|c|c|c|c|c|c|c|c|}
\hline & \multicolumn{3}{|c|}{ USA } & \multicolumn{3}{|c|}{ Japan } & \multicolumn{3}{|c|}{ OECD9 } & \multicolumn{3}{|c|}{ EU6 } \\
\hline & $\begin{array}{r}\text { EFF } \\
\text { Effect }\end{array}$ & $\begin{array}{r}\text { STR } \\
\text { Effect }\end{array}$ & $\begin{array}{r}\text { TOT } \\
\text { Effect }\end{array}$ & $\begin{array}{r}\text { EFF } \\
\text { Effect }\end{array}$ & $\begin{array}{r}\text { STR } \\
\text { Effect }\end{array}$ & $\begin{array}{r}\text { TOT } \\
\text { Effect }\end{array}$ & $\begin{array}{r}\text { EFF } \\
\text { Effect }\end{array}$ & $\begin{array}{r}\text { STR } \\
\text { Effect }\end{array}$ & $\begin{array}{r}\text { TOT } \\
\text { Effect }\end{array}$ & $\begin{array}{r}\text { EFF } \\
\text { Effect }\end{array}$ & $\begin{array}{r}\text { STR } \\
\text { Effect }\end{array}$ & $\begin{array}{r}\text { TOT } \\
\text { Effect }\end{array}$ \\
\hline Sale, maintenance, repair motor vehicles and -cycles; retail sale of fuel & -32.3 & 23.2 & -9.0 & -0.2 & 0.8 & 0.6 & -37.7 & 23.8 & -13.8 & 14.6 & -15.2 & -0.6 \\
\hline Other wholesale trade and commission trade & -15.9 & -4.5 & -20.4 & 3.1 & -10.7 & -7.6 & -25.1 & -12.8 & -37.9 & -20.4 & 25.3 & 4.9 \\
\hline Other retail trade; repair of household goods & -51.4 & 25.5 & -25.9 & -9.6 & -63.1 & -72.7 & -86.5 & 18.3 & -68.1 & 32.2 & -12.2 & 20 \\
\hline Hotels and restaurants & -7.1 & -8.1 & -15.2 & 82.5 & -45.4 & 37.2 & 8.2 & -27.3 & -19.1 & 22.1 & -15.9 & 6.2 \\
\hline Financial intermediation, except insurance and pension funding & -7.5 & 7.0 & -0.5 & -2.5 & 1.7 & -0.8 & -16.4 & 14.9 & -1.4 & -28.3 & 14.9 & -13.4 \\
\hline Insurance and pension funding, except compulsory social security & 0.5 & -1.4 & -0.9 & 3.5 & -5.0 & -1.5 & 3.9 & -6.4 & -2.5 & 19 & -21.1 & -2.1 \\
\hline Activities related to financial intermediation & - & - & - & - & - & - & -0.4 & 1.2 & 0.8 & -3.9 & 9.6 & 5.7 \\
\hline Renting of machinery and equipment & 6.9 & -4.4 & 2.5 & -13.9 & 13.4 & -0.5 & 3.8 & 2.4 & 6.2 & 4.3 & 1.2 & 5.5 \\
\hline Computer and related activities & -1.0 & 2.7 & 1.7 & -4.4 & 3.1 & -1.3 & -7.8 & 12.2 & 4.3 & -13.4 & 25.5 & 12.1 \\
\hline Research and development & 1.1 & 0.2 & 1.3 & 11.4 & 1.7 & 13.0 & 6.7 & -0.2 & 6.5 & 11.3 & -11.0 & 0.3 \\
\hline Public administration and defence; Compulsory social security & 9.3 & -26.7 & -17.5 & -13.7 & -11.2 & -24.9 & 23.8 & -65.7 & -41.9 & 55.0 & -63.2 & -8.2 \\
\hline Education & 1.0 & -1.1 & -0.1 & 29.6 & -11.2 & 18.4 & 22.7 & -11.3 & 11.4 & 82.3 & -42.1 & 40.2 \\
\hline Health and social work & -5.4 & -0.7 & -6.1 & 14.0 & 48.5 & 62.6 & 26.5 & -0.4 & 26.1 & 39.9 & -24.2 & 15.7 \\
\hline Sewage and refuse disposal, sanitation and similar activities & 1.4 & -4.7 & -3.3 & 2.1 & -2.0 & 0.1 & -0.5 & -3.8 & -4.3 & -0.1 & 3.5 & 3.4 \\
\hline Activities of membership organizations n.e.c. & -1.0 & -2.6 & -3.5 & -0.2 & -0.8 & -1.0 & 0.1 & -5.9 & -5.8 & 5.9 & -7.8 & -1.9 \\
\hline Recreational, cultural and sporting activities & -2.4 & 1.4 & -1.0 & 14.9 & -9.2 & 5.6 & -2.9 & 2.8 & 0.0 & -12.7 & 9.6 & -3.1 \\
\hline Other service activities & -2.7 & -1.0 & -3.7 & 14.4 & -4.3 & 10.1 & 0.1 & -5.8 & -5.7 & -1.1 & -4.1 & -5.2 \\
\hline SERVICES & -110.1 & 10.1 & -100.0 & 160.8 & -60.8 & 100.0 & -73.8 & -26.2 & -100.0 & 113.8 & -13.8 & 100 \\
\hline
\end{tabular}


Table 10c. Percentage contribution of the efficiency effect $(E F F)$ and the structure effect (STR) by sector to the annual growth rate of service sector energy intensity (TOT) in the period 1995-2005. GDP-weighted cross-country averages.

\begin{tabular}{|c|c|c|c|c|c|c|c|c|c|}
\hline & \multicolumn{3}{|c|}{ OECD18 } & \multicolumn{3}{|c|}{ EU15 } & \multicolumn{3}{|c|}{ EU4 } \\
\hline & EFF & STR & TOT & $\mathrm{EFF}$ & STR & TOT & EFF & STR & TOT \\
\hline Sale, maintenance, repair motor vehicles and -cycles; retail sale of fuel & -19.0 & 12.4 & -6.6 & 2.5 & -1.4 & 1.1 & 1.9 & 2.2 & 4.1 \\
\hline Other wholesale trade and commission trade & -40.3 & -3.0 & -43.2 & -63.1 & 13.0 & -50.1 & -79.1 & 31.6 & -47.4 \\
\hline Other retail trade; repair of household goods & -49.5 & 8.6 & -40.9 & -1.7 & -4.2 & -5.9 & -24.1 & 2.5 & -21.5 \\
\hline Hotels and restaurants & 3.6 & -17.0 & -13.4 & -1.5 & -6.2 & -7.7 & -4.2 & -7.3 & -11.5 \\
\hline Financial intermediation, except insurance and pension funding & -9.5 & 9.6 & 0.1 & -5.2 & 4.6 & -0.6 & -2.8 & 3.5 & 0.6 \\
\hline Insurance and pension funding, except compulsory social security & 4.4 & -4.7 & -0.2 & 8.8 & -6.4 & 2.4 & 4.6 & 2.7 & 7.2 \\
\hline Activities related to financial intermediation & -0.1 & 0.6 & 0.4 & -0.3 & 1.3 & 0.9 & -1.3 & 0.7 & -0.6 \\
\hline Renting of machinery and equipment & 1.3 & 2.4 & 3.7 & -0.9 & 1.4 & 0.6 & -0.3 & 0.3 & 0.0 \\
\hline Public administration and defence; Compulsory social security & 14.1 & -39.4 & -25.3 & 10.1 & -17.8 & -7.7 & -1.3 & -0.1 & -1.4 \\
\hline Education & 12.2 & -9.2 & 3.0 & 12.6 & -13.1 & -0.5 & 7.1 & -2.7 & 4.4 \\
\hline Health and social work & 2.8 & 0.1 & 2.9 & -22.1 & -3.8 & -25.9 & 1.5 & -9.8 & -8.3 \\
\hline Sewage and refuse disposal, sanitation and similar activities & 4.8 & -6.2 & -1.4 & 6.4 & -3.8 & 2.6 & 4.9 & 0.2 & 5.0 \\
\hline Activities of membership organizations n.e.c. & -0.2 & -3.6 & -3.7 & -0.1 & -2.1 & -2.2 & -0.8 & 0.0 & -0.8 \\
\hline Recreational, cultural and sporting activities & -1.4 & 1.4 & 0.1 & -2.8 & 1.9 & -0.9 & -0.1 & -0.1 & -0.2 \\
\hline Other service activities & 0.9 & -5.3 & -4.3 & -0.7 & -3.4 & -4.1 & 1.4 & -4.5 & -3.2 \\
\hline SERVICES & -77.8 & -22.2 & -100.0 & -86.4 & -13.6 & -100.0 & -126.6 & 26.6 & -100.0 \\
\hline
\end{tabular}




\section{Regression analysis}

In the final part of our analysis, we delve deeper into the fundamental question what factors may drive the observed temporal and spatial variation in energy intensity in the service sector. We follow the tradition in the economic growth literature known as Barro-regressions (after Barro, 1991) in which we try to explain variation in productivity levels (the inverse of the intensity levels that we used before) from a series of 'plausible' explanatory variables. The explanatory variables that we consider are (i) ICT intensity, (ii) energy prices, and (iii) indicators for climate conditions. We exploit the panel structure of our data by using country- and/or time fixed effects to control for unobserved heterogeneity across countries and global trends over time. This helps us to clarify to what extent there is evidence for two intuitively plausible explanations for the relatively poor performance of the service sector in terms of energy efficiency improvements. The first explanation builds on the hypothesis that the low share of energy costs in total production costs that is characteristic for most service sectors gives firms little incentive to save on energy costs (see, e.g., De Groot et al. 2001). A natural implication of this would be that energy prices bear little relation with energy efficiency improvements. A second explanation focuses on the transformation in many service sectors resulting from the emergence of ICT in the course of the 1990s. This may have resulted in a transformation towards more energy-intensive production processes and could be an explanation for the relatively slow increase in energy productivity in the service sector.

Our proxy for ICT intensity is defined as ICT capital services per hour worked. Figure 6 shows that ICT intensity has increased considerably in most OECD18 countries since 1995, and furthermore, that it varies substantially across countries. Figure 7 shows the variation of energy ICT intensity across sectors. It clearly reveals that the Post and Telecommunication sector, Financial Intermediation and Renting, Computer, R\&D and Other Business stand out as ICT intensive (sub-) sectors, both within the service sector as well as compared to the manufacturing sector and the aggregate economy. 


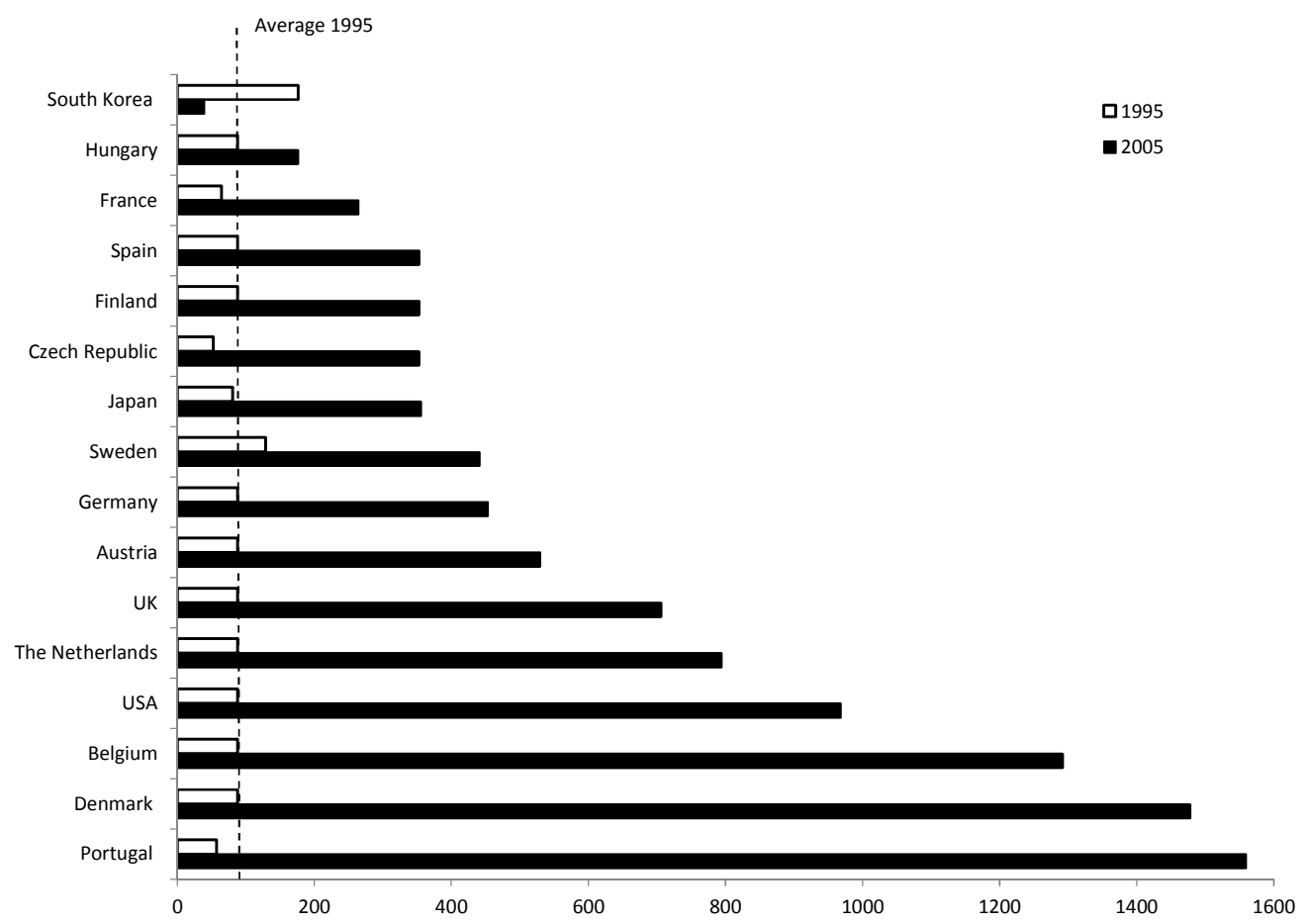

Figure 6. ICT intensity across OECD18 countries, 1995 and 2005 (Indexed; Average OECD18 in 1995=100)

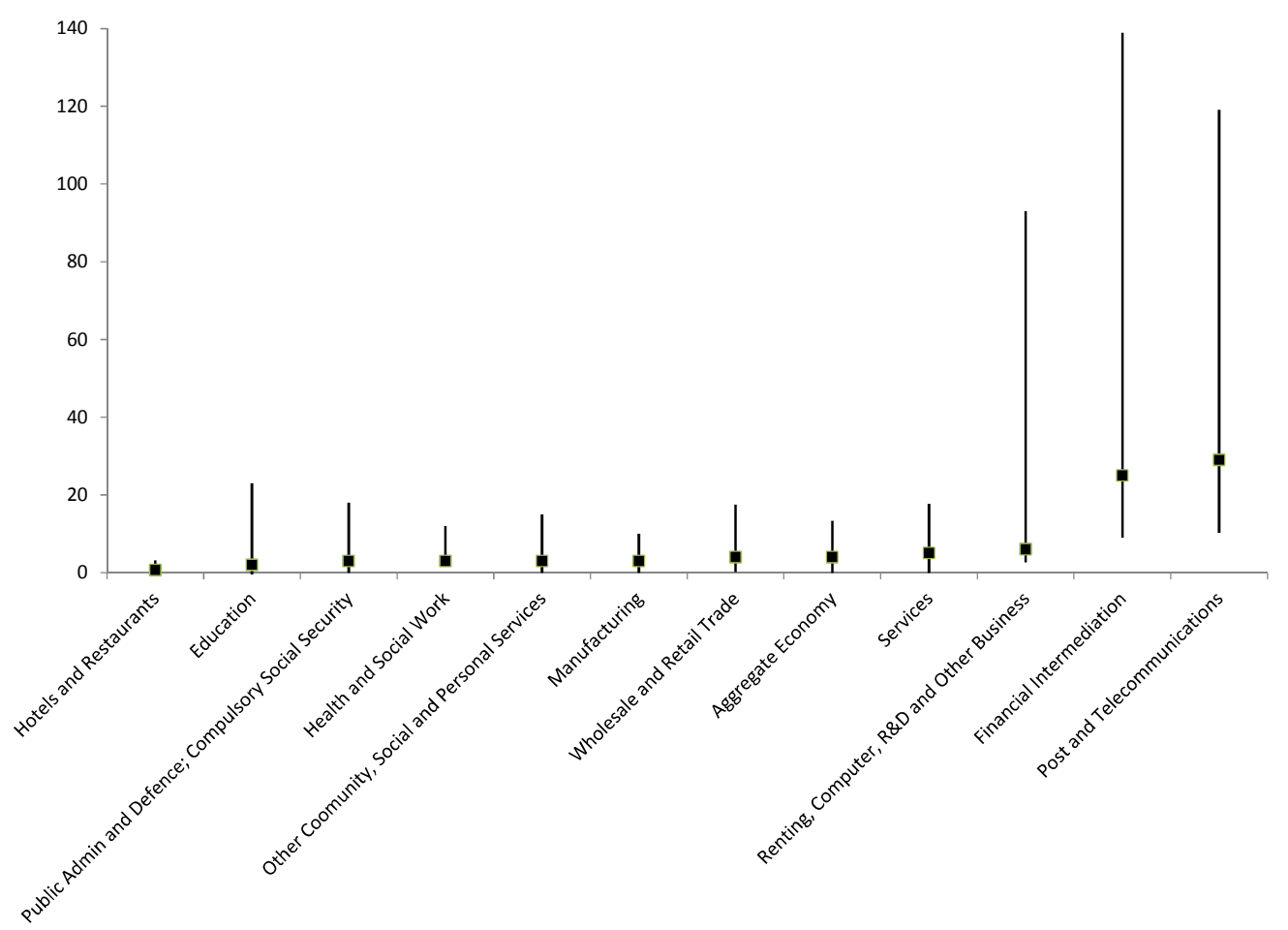

Figure 7. ICT intensity in 2005 per sector (minimum, maximum and medium value for OECD countries) 
In order to determine the effect of the various explanatory variables on the growth of energy intensity, we estimate the following equation for all (sub-)sectors in our sample for the period 1980-2005:6

$$
g_{i t}=\alpha_{i}+\beta_{1} \cdot \ln \left(E P_{i t-1}\right)+\beta_{2} \cdot P_{i t}+\beta_{3} \cdot I C T_{i t}+\beta_{4} \cdot H E A T_{i t}+\beta_{5} \cdot C O O L_{i t}+\gamma_{t}+\varepsilon_{i t}
$$

where $g_{i t}$ is the growth of energy productivity in country $i$ at time $t$ (defined as the dlog of energy productivity in the final and initial year of the period considered), $\alpha_{i}$ are country-fixed effects, $E P_{i t-1}$ is initial energy productivity, $P_{i t}$ is the energy price, $I C T_{i t}$ is the ICT intensity, $H E A T_{i t}$ and $C O O L_{i t}$ are the number of heating and cooling days, respectively, and $\gamma_{t}$ are period fixed effects. In our estimation strategy, we have used two different samples (OECD9 and the complete sample of countries), and we have estimated equation (1) without any fixed effect, with only country fixed effects, and with country and period fixed effects. Finally, we have estimated the equation on a year-to-year basis and also for 5year periods to eliminate business cycle effects (as is rather common in the literature, cf. Islam 1995). The results reported in Table 12 are for the complete sample for 5-year periods, and with inclusion of countryand period fixed effects. Other results are available upon request.

We see from Table 12 clear evidence for $\beta$-convergence in terms of energy productivity in all sectors: across all sectors we find a statistically significant tendency of countries with relatively low initial productivity levels to grow relatively fast. This effect is about equally strong in the service sectors as in the manufacturing sector and the aggregate economy. Looking at the country specific fixed effects (see the Appendix for the country fixed effects), we see relatively good performance across (almost) all sectors in Finland, Denmark and Sweden. The Czech Republic, Japan, Korea, and Portugal stand out negatively.

Regarding the impact of ICT, our regression results analysis yield various important results. First, looking at the time fixed effects we observe a clearly declining trend in energy productivity over time (which is much stronger than in the manufacturing industry). There may of course be various reasons driving this common trend across countries, but the introduction of ICT is a natural candidate. Second, if we look at the additional results in Table 12, we see that the results for the impact of ICT intensity are mixed. In most sectors, there is hardly any statistically significant relationship between ICT and energy productivity. Exceptions are wholesale retail trade, the aggregate service sector and the total economy. In these sectors, relatively fast introduction of ICT (in deviation from the common trend which is captured by the time fixed effects) is associated with relatively high energy productivity. This may be caused by a vintage effect, implying the adoption of relatively energy-extensive ICT equipment. Third, also for energy prices, we find no clear relationship between energy productivity levels and a relatively fast increase of energy prices (note again that global trends in energy prices and structural cross-country variation in prices is captured by the fixed effects). This may just reflect the fact that energy prices vary little across time and countries, but it may also be the result of limited responsiveness of economic actors to energy

\footnotetext{
${ }^{6}$ We leave out sector-indices.
} 
prices. The latter would confirm the hypothesis that in the service sectors firms have little incentives to invest in energy saving, presumably because its low share of energy costs in total production costs.

Table 12. Regression results per sector

\begin{tabular}{|c|c|c|c|c|c|c|c|c|c|c|c|c|}
\hline Sector & TRA & HOT & TEL & FIN & OBU & ADM & EDU & HEA & SOC & SRV & MAN & TOT \\
\hline \multirow[t]{2}{*}{ Constant } & $1.42^{* * *}$ & $1.68^{* * *}$ & $1.79^{* * *}$ & $2.69^{* * *}$ & $2.46^{* * *}$ & $1.11^{* *}$ & $1.92^{* *}$ & $1.68^{* * *}$ & $1.83^{* * *}$ & $1.80^{* * *}$ & $1.04^{* *}$ & $1.78^{* * *}$ \\
\hline & 0.31 & 0.58 & 0.51 & 0.94 & 0.59 & 0.43 & 0.79 & 0.62 & 0.39 & 0.48 & 0.47 & 0.50 \\
\hline \multirow[t]{2}{*}{ Initial productivity } & $-0.68^{* * * *}$ & $-0.66^{* * *}$ & $-0.39^{* * * *}$ & $-0.58^{* * * *}$ & $-0.62^{* * * *}$ & $-0.48^{* * *}$ & $-0.48^{* *}$ & $-0.46^{* * *}$ & $-0.58^{* * *}$ & $-0.56^{* * *}$ & $-0.66^{* * *}$ & $-0.62^{* * *}$ \\
\hline & 0.12 & 0.15 & 0.13 & 0.19 & 0.17 & 0.12 & 0.22 & 0.15 & 0.15 & 0.15 & 0.22 & 0.20 \\
\hline \multirow[t]{2}{*}{ ICT intensity } & $0.06^{* * * *}$ & -0.12 & 0.00 & 0.00 & 0.00 & 0.03 & 0.01 & -0.01 & 0.01 & $0.04^{* * *}$ & 0.03 & $0.05^{*}$ \\
\hline & 0.02 & 0.12 & 0.00 & 0.01 & 0.00 & 0.02 & 0.02 & 0.05 & 0.02 & 0.02 & 0.05 & 0.03 \\
\hline \multirow[t]{2}{*}{ Energy price } & $0.50^{* * * *}$ & 0.20 & -0.07 & 0.23 & 0.07 & 0.11 & 0.21 & 0.07 & 0.03 & 0.22 & 0.45 & 0.12 \\
\hline & 0.15 & 0.20 & 0.34 & 0.25 & 0.14 & 0.07 & 0.14 & 0.12 & 0.14 & 0.16 & 0.31 & 0.35 \\
\hline \multirow[t]{2}{*}{ Heating days } & 1.76 & 0.16 & $-0.23^{*}$ & -0.69 & $-0.91^{* * *}$ & -0.36 & $-3.81^{* *}$ & -1.53 & -0.22 & -7.55 & $-2.49^{* *}$ & $-14.70^{*}$ \\
\hline & 1.58 & 0.27 & 0.13 & 0.68 & 0.30 & 1.43 & 1.63 & 1.90 & 0.44 & 5.46 & 1.11 & 7.92 \\
\hline \multirow[t]{2}{*}{ Cooling days } & $-16.70^{* * *}$ & $-5.31^{*}$ & 0.09 & -4.67 & 3.37 & $55.91^{* *}$ & 39.61 & 14.76 & -0.29 & 34.31 & 2.07 & 32.97 \\
\hline & 6.02 & 2.88 & 0.48 & 3.1 & 3.05 & 25.41 & 25.9 & 9.63 & 2.52 & 62.74 & 10.61 & 83.38 \\
\hline \multicolumn{13}{|l|}{ Period fixed effects } \\
\hline 1980-1985 & -0.07 & 0.14 & 0.02 & 0.08 & 0.05 & 0.06 & 0.03 & -0.03 & 0.07 & 0.08 & 0.00 & 0.09 \\
\hline 1985-1990 & 0.00 & 0.04 & 0.06 & -0.07 & -0.06 & -0.05 & 0.18 & 0.18 & 0.07 & 0.06 & 0.04 & 0.07 \\
\hline 1990-1995 & 0.10 & -0.06 & 0.08 & -0.04 & 0.08 & 0.00 & -0.03 & -0.11 & -0.01 & 0.04 & -0.04 & -0.01 \\
\hline 1995-2000 & 0.09 & -0.08 & -0.09 & 0.00 & -0.02 & 0.02 & -0.02 & -0.01 & -0.04 & 0.00 & 0.03 & -0.02 \\
\hline 2000-2005 & -0.12 & -0.03 & -0.08 & 0.02 & -0.05 & -0.03 & -0.16 & -0.03 & -0.09 & -0.19 & -0.03 & -0.13 \\
\hline Adjusted $\mathrm{R}^{2}$ & 0.52 & 0.24 & 0.14 & 0.15 & 0.31 & 0.38 & 0.29 & 0.20 & 0.27 & 0.35 & 0.37 & 0.32 \\
\hline \# obs & 69 & 69 & 66 & 69 & 69 & 69 & 69 & 69 & 69 & 66 & 60 & 55 \\
\hline
\end{tabular}

Notes: statistical significance is indicated with stars: ${ }^{* * *},{ }^{* *}$, and ${ }^{*}$ stand for statistical significance at the 1,5 and $10 \%$, respectively. White standard errors are reported in brackets below the estimates. All equations have been estimated with periodand country-specific fixed effects. The sectors are labeled as follows: TRA: Wholesale and retail trade; HOT: Hotels and restaurants; TEL: Post and telecommunications; FIN: Financial intermediation; OBU: Renting, computer, R\&D and other business; ADM: Public admin and defence; compulsory social security; EDU: Education; HEA: Health and social work; SOC: Other community, social and personal services; SRV: Services; MAN: Manufacturing; TOT: Aggregate economy. The period fixed effects are centered around zero. Country fixed effects are reported in Table A4 in the Appendix.

Finally, in contrast, for the climate related variables we see several statistically significant relationships between energy productivity and the number of heating and cooling days. In relatively cold areas, the energy productivity is relatively low as is to be expected. This pattern is particularly strong in education (where energy use is almost largely related to heating of buildings). The pattern is also clearly present at the aggregate service sector level and for the aggregate economy. For cooling we see a more mixed pattern. Many cooling days may be associated with relatively high energy productivity because of less need for heating. But it may also lower energy productivity if, for example, air-conditioning is required. 


\section{Conclusions}

Based on a unique dataset, this paper has provided an extensive analysis of the dynamics of energy intensity in the service sector. It aims to fill a gap in the existing literature that has hitherto mainly focused on the energy intensive manufacturing sector. We show that although energy-intensity is indeed low in the service sectors compared to the manufacturing sector, the service sector becomes increasingly important as a consumer of energy and tends to remain behind in terms of energy efficiency improvements. The latter may be caused by technological developments within the service sector that may turn them less energy efficient, but the service sector is also known for its (relative) lack of attention for energy savings as seems to be confirmed by the results in this paper. As such, the paper calls for enhanced attention for the potential of energy savings in the service sectors. In view of the low share of energy in total costs, the policies that will be called for are most likely to be of different nature than traditional tax and subsidy programs (see, e.g. De Groot et al. 2001 and Florax et al. 2011). This is further reinforced by the results of this paper which reveal that energy prices can hardly explain variation in energy productivity levels. In some sectors, we see a positive effect of ICT intensity on energy productivity. This may be the resultant of smart energy systems or rapid developments in the energy efficiency of ICT (a vintage effect). Future research can elaborate on this analysis by further expanding the coverage across time and countries. Also a deeper investigation of the determinants of temporal and spatial variation in energy efficiency in the service sector, including attention for the impact of variation in policy mixes, is called for. 


\section{References}

Aldy, J. (2006). 'Per Capita Carbon Dioxide Emissions: Convergence or Divergence?', Environmental and Resource Economics, 33, pp. 533-555.

Ang B.W., F.L. Liu and H. Chung (2004). 'A Generalized Fisher Index Approach to Energy Decomposition Analysis', Energy Economics, 26, pp. 757-763.

Ang, B.W. (2004). 'Decomposition for Policymaking in Energy: Which is the Preferred Method?', Energy Policy, 32, pp. 1131-1139.

Ang, B.W. and F.L. Liu (2001). 'A New Energy Decomposition Method: Perfect in Decomposition and Consistent in Aggregation', Energy, 26, pp. 537-547.

Ang, B.W. and F.Q. Zhang (2000). 'A Survey of Index Decomposition Analysis in Energy and Environmental Studies', Energy, 25, pp. 1149-1176.

Ang, B.W., F.L. Liu and E.P. Chew (2003). 'Perfect decomposition techniques in energy and environmental analysis', Energy Policy, 31, pp. 1561-1566.

Barro, R.J. (1991). 'Economic Growth in a Cross-Section of Countries', Quarterly Journal of Economics, 106, pp. 407-443.

Barro, R.J. and X. Sala-i-Martin (1992). 'Convergence', Journal of Political Economy, 100, pp. 223-251.

Boyd, G.A. and J.M. Roop (2004). 'A Note on the Fisher Ideal Index Decomposition for Structural Change in Energy Intensity’, Energy Journal, 25, pp. 87-101.

De Groot, H.L.F., E.T. Verhoef and P. Nijkamp (2001). 'Energy Saving by Firms: Decision-Making, Barriers and Policies,' Energy Economics, 23 (6), pp. 717-740.

Duro, J.A. and E. Padilla (2011). 'Inequality across Countries in Energy Intensities: An Analysis of the Role of Energy Transformation and Final Energy Consumption', Energy Economics, 33, pp. 474479.

Duro, J.A., V. Alcántara and E. Padilla (2010). 'International Inequality in Energy Intensity Levels and the Role of Production Composition and Energy Efficiency: An Analysis of OECD Countries', Ecological Economics, 69 (12), pp. 2468-2474.

Eichhammer, W. and W. Mannsbart (1997). 'Industrial Energy Efficiency: Indicators for a European Cross-Country Comparison of Energy Efficiency in the Manufacturing Industry', Energy Policy, 25, pp. 759-772.

Florax, R.J.G.M., H.L.F. de Groot and P. Mulder (2011). Improving Energy Efficiency through Technology: Trends, Investment Behaviour and Policy Design, Cheltenham: Edward Elgar.

Howarth, R.B., L. Schipper, P.A. Duerr and S. Strøm (1991). 'Manufacturing Energy Use in 8 OECD Countries', Energy Economics, 13, pp. 135-142.

Huntington, H.G. (2010). 'Structural Change and U.S. Energy Use: Recent Patterns', Energy Journal, 31, pp. 25-39.

Islam, N. (1995). 'Growth Empirics: A Panel Data Approach', Quarterly Journal of Economics, 4, pp. $1127-1170$.

Jorgenson, D.W. (1984). 'The Role of Energy in Productivity Growth', Energy Journal, 5, pp. 11-26.

Liddle, B. (2009). 'Electricity Intensity Convergence in IEA/OECD Countries: Aggregate and Sectoral Analysis', Energy Policy, 37, pp. 1470-1478. 
Liu, N. and B.W. Ang (2007). 'Factors Shaping Aggregate Energy Intensity Trend for Industry: Energy Intensity versus Product Mix', Energy Economics, 29, pp. 609-635.

Mairet, N. and F. Decellas (2009). 'Determinants of Energy Demand in the French Service Sector: A Decomposition Analysis', Energy Policy, 37, pp. 2733-2744.

Markandya, A, A. Pedroso-Galinato and D. Streimikiene (2006). 'Energy Intensity in Transition Economies: Is There Convergence Towards the EU Average?', Energy Economics, 28 (1), pp. 121145.

Miketa, A. and P. Mulder (2005). 'Energy-Productivity Across Developed and Developing Countries in 10 Manufacturing Sectors: Patterns of Growth and Convergence', Energy Economics, 27, pp. 429453.

Mulder, P. and H.L.F. de Groot (2007). 'Sectoral Energy- and Labour Productivity Convergence', Environmental and Resource Economics, 36, pp. 85-112.

Mulder, P. and H.L.F. de Groot (2012), 'Structural Change and Convergence of Energy Intensity across OECD Countries, 1970-2005', Energy Economics, 34, pp. 1910-1921.

O'Mahony, M. and M.P. Timmer (2009). 'Output, Input and Productivity Measures at the Industrial Level: The EU KLEMS Database', Economic Journal, 119, pp. F347-F403.

Park, S.H., B. Dissmann and K.Y. Nam (1993). 'A Cross-Country Decomposition Analysis of Manufacturing Energy Consumption', Energy, 18, pp. 843-858.

Quah, D. (1993). 'Galton's Fallacy and Test of the Convergence Hypothesis', Scandinavian Journal of Economics, 95, pp. 427-443.

Romero-Avila, D. (2008). 'Convergence in Carbon Dioxide Emissions among Industrial Countries Revisited', Energy Economics, 30, pp. 2265-2282.

Unander, F. (2007). 'Decomposition of Manufacturing Energy-Use in IEA Countries; How Do Recent Developments Compare with Historical Long-Term Trends?', Applied Energy, 84, pp. 771-780.

Zhang, F.Q. and B.W. Ang (2001). 'Methodological Issues in Cross-Country/Region Decomposition of Energy and Environmental Indicators', Energ y Economics, 23, pp. 179-190. 


\section{Appendix}

Table A.la Average annual growth rates energy intensity by sector for the periods 1980-2005, 1980-1995 and $1995-2005$.

\begin{tabular}{|c|c|c|c|c|c|c|c|c|c|c|c|c|c|c|c|c|c|c|}
\hline & AUT & BEL & CZE & DNK & FIN & FRA & GER & HUN & JPN & KOR & NLD & POL & PRT & SPA & SVK & SWE & UKD & USA \\
\hline \multicolumn{19}{|c|}{ WHOLESALE AND RETAIL TRADE } \\
\hline 1980-2005 & 2.7 & -1.4 & - & -3.1 & 1.6 & -3.3 & -1.1 & - & 0.0 & -2.8 & -0.6 & - & -5.1 & 0.3 & - & - & 2.0 & -3.8 \\
\hline 1980-1995 & 4.0 & 3.2 & - & -2.3 & 1.5 & -4.9 & -0.9 & - & 0.5 & -5.7 & 1.6 & - & -8.6 & -3.3 & - & - & 2.0 & -4.4 \\
\hline 1995-2005 & 0.8 & -8.3 & 0.0 & -4.3 & 1.9 & -1.0 & -1.5 & -12.8 & -0.8 & 1.4 & -2.3 & -2.0 & 0.3 & 5.8 & -10.5 & -4.9 & 2.2 & -2.9 \\
\hline \multicolumn{19}{|c|}{ Sale, maintenance and repair of motor vehicles and motorcycles; retail sale of fuel } \\
\hline 1980-2005 & 2.6 & 3.3 & - & 3.6 & 0.9 & -0.4 & 1.2 & - & 5.0 & -2.7 & 1.2 & - & -7.4 & -2.1 & - & - & 0.6 & -4.6 \\
\hline 1980-1995 & 4.4 & 2.7 & - & 7.3 & 1.4 & 0.0 & 2.4 & - & 8.5 & -5.4 & 3.8 & - & -8.6 & -5.6 & - & - & -2.2 & -4.3 \\
\hline 1995-2005 & -0.1 & 4.1 & 9.7 & -1.9 & 0.2 & -0.9 & -0.6 & -0.6 & -0.2 & 1.4 & -0.9 & -3.2 & -5.6 & 3.1 & -2.0 & -5.0 & 4.7 & -5.1 \\
\hline \multicolumn{19}{|c|}{ Other wholesale trade and commission trade } \\
\hline 1980-2005 & 1.9 & -3.8 & - & -4.8 & 2.4 & -4.3 & -3.1 & - & -1.9 & -2.7 & -0.5 & - & -4.7 & -0.4 & - & - & 3.1 & -4.3 \\
\hline 1980-1995 & 2.9 & 3.3 & - & -4.5 & 2.1 & -5.7 & -2.1 & - & -3.4 & -5.4 & 1.7 & - & -8.6 & -3.1 & - & - & 3.9 & -6.2 \\
\hline 1995-2005 & 0.4 & -14.5 & 0.2 & -5.3 & 2.8 & -2.1 & -4.7 & -21.4 & 0.3 & 1.4 & -2.3 & -1.0 & 1.2 & 3.5 & -4.6 & -4.9 & 2.0 & -1.5 \\
\hline \multicolumn{19}{|c|}{ Other retail trade } \\
\hline 1980-2005 & 3.9 & 1.7 & - & -2.9 & 0.3 & -3.2 & 0.4 & - & 1.8 & -2.9 & 0.1 & - & 1.6 & 2.9 & - & - & 1.5 & -3.2 \\
\hline 1980-1995 & 5.5 & 2.4 & - & -2.4 & 0.3 & -5.0 & -0.3 & - & 3.3 & -5.8 & 2.3 & - & 0.9 & -0.8 & - & - & 1.2 & -2.5 \\
\hline 1995-2005 & 1.6 & 0.6 & -8.3 & -3.7 & 0.3 & -0.6 & 1.4 & 7.3 & -0.5 & 1.4 & -1.6 & -3.3 & 2.8 & 8.3 & -17.8 & -5.0 & 1.8 & -4.2 \\
\hline \multicolumn{19}{|c|}{ HOTELS AND RESTAURANTS } \\
\hline 1980-2005 & 1.9 & 2.8 & - & 0.7 & 0.4 & 3.1 & -1.8 & - & 3.5 & -5.2 & 2.1 & - & -0.6 & -0.7 & - & - & 0.0 & -0.3 \\
\hline 1980-1995 & 1.8 & 0.7 & - & 2.3 & 0.8 & 4.3 & -1.8 & - & 3.1 & -9.4 & 4.1 & - & 1.4 & -1.8 & - & - & -1.2 & 0.1 \\
\hline 1995-2005 & 2.0 & 6.0 & -1.9 & -1.8 & -0.3 & 1.4 & -1.9 & -3.2 & 4.1 & 1.1 & 0.5 & -3.1 & -3.6 & 1.0 & 5.2 & -0.7 & 1.8 & -1.1 \\
\hline \multicolumn{19}{|c|}{ POST AND TELECOMMUNICATION } \\
\hline 1980-2005 & 6.8 & 0.9 & - & -6.9 & -8.6 & -0.5 & -2.1 & - & 1.5 & -2.1 & -6.3 & - & -7.2 & 0.1 & - & - & -1.7 & -2.6 \\
\hline 1980-1995 & 2.5 & 2.6 & - & -5.5 & -5.1 & 2.0 & -3.0 & - & -0.2 & -1.9 & -6.2 & - & -9.9 & -3.4 & - & - & 0.1 & -2.1 \\
\hline $1995-2005$ & 13.3 & -1.6 & -5.4 & -8.9 & -13.9 & -4.4 & -0.9 & -7.0 & 4.2 & -2.3 & -6.3 & -14.1 & -3.2 & 5.4 & -4.0 & -6.1 & -4.3 & -3.3 \\
\hline
\end{tabular}


Table A.1b Average annual growth rates energy intensity by sector for the periods 1980-2005, 1980-1995 and 1995-2005.

\begin{tabular}{|c|c|c|c|c|c|c|c|c|c|c|c|c|c|c|c|c|c|c|}
\hline & AUT & BEL & CZE & DNK & FIN & FRA & GER & HUN & JPN & KOR & NLD & POL & PRT & SPA & SVK & SWE & UKD & USA \\
\hline \multicolumn{19}{|c|}{ FINANCIAL INTERMEDIATION } \\
\hline 1980-2005 & 6.8 & 0.3 & - & -8.0 & 3.8 & -0.5 & -0.1 & - & -1.3 & -0.9 & 1.3 & - & -0.1 & -2.5 & - & - & 0.7 & -1.3 \\
\hline 1980-1995 & 4.5 & 3.7 & - & -8.7 & 3.7 & -1.2 & -3.1 & - & -2.1 & -2.4 & 4.7 & - & 3.9 & -1.2 & - & - & 3.5 & -1.1 \\
\hline 1995-2005 & 10.2 & -4.9 & -1.2 & -7.0 & 4.0 & 0.6 & 4.4 & -3.5 & 0.0 & 1.5 & -1.4 & 5.6 & -6.0 & -4.5 & -2.7 & -3.3 & -3.3 & -1.7 \\
\hline \multicolumn{19}{|c|}{ Financial intermediation, except insurance and pension funding } \\
\hline 1980-2005 & 7.1 & - & - & -6.6 & 4.6 & -1.8 & - & - & -1.5 & -0.8 & 1.2 & - & - & -3.7 & - & - & 1.1 & -2.6 \\
\hline $1980-1995$ & 4.1 & - & - & -5.9 & 5.1 & -2.9 & - & - & -1.8 & -2.4 & 5.0 & - & - & -1.9 & - & - & 6.3 & -2.5 \\
\hline 1995-2005 & 11.8 & - & -1.6 & -7.7 & 3.8 & -0.2 & 1.3 & -3.7 & -0.9 & 1.5 & -1.9 & 4.6 & -6.4 & -6.4 & -7.0 & -1.3 & -6.7 & -2.8 \\
\hline \multicolumn{19}{|c|}{ Insurance and pension funding, except compulsory social security } \\
\hline 1980-2005 & 4.3 & - & - & -8.8 & 0.7 & 14.6 & - & - & -0.6 & -0.8 & 1.0 & - & - & -3.6 & - & - & -0.8 & 1.0 \\
\hline $1980-1995$ & 5.4 & - & - & -10.9 & -14.4 & 19.4 & - & - & -2.6 & -2.4 & 1.6 & - & - & -4.9 & - & - & -3.4 & 1.0 \\
\hline $1995-2005$ & 2.6 & - & 11.0 & -5.7 & 23.4 & 7.4 & 13.2 & -12.6 & 2.3 & 1.5 & 0.5 & 15.6 & -4.4 & -1.5 & 9.3 & -1.8 & 3.3 & 1.0 \\
\hline \multicolumn{19}{|c|}{ Activities related to financial intermediation } \\
\hline 1980-2005 & 5.7 & - & - & -14.0 & 0.9 & -14.9 & - & - & - & - & 2.6 & - & - & -0.1 & - & - & 4.1 & - \\
\hline $1980-1995$ & 5.6 & - & - & -19.5 & -5.2 & -20.9 & - & - & - & - & 9.8 & - & - & 0.0 & - & - & 6.3 & - \\
\hline $1995-2005$ & 5.7 & - & - & -5.8 & 9.9 & -6.0 & 9.0 & 7.1 & - & 1.5 & -3.3 & -21.6 & 1.1 & -0.3 & - & 0.7 & 0.8 & - \\
\hline \multicolumn{19}{|c|}{ PUBLIC ADMINISTRATION AND DEFENCE } \\
\hline 1980-2005 & 1.5 & 10.5 & - & -3.3 & 4.5 & -2.0 & -2.5 & - & 3.0 & 7.0 & 3.8 & - & 4.9 & 4.6 & - & - & 3.8 & 0.8 \\
\hline 1980-1995 & 1.3 & 12.5 & - & -4.0 & 4.3 & -3.1 & -4.7 & - & 5.4 & 9.9 & 7.1 & - & 9.3 & 3.2 & - & - & 4.6 & 0.7 \\
\hline 1995-2005 & 1.9 & 7.5 & 2.8 & -2.3 & 4.8 & -0.4 & 0.8 & 0.3 & -0.6 & 2.7 & 1.1 & 1.1 & -1.7 & 6.6 & -8.6 & -2.0 & 2.5 & 0.9 \\
\hline \multicolumn{19}{|l|}{ EDUCATION } \\
\hline 1980-2005 & 9.1 & 7.6 & - & -3.5 & 2.1 & -0.2 & -2.5 & - & 3.9 & 1.9 & 0.9 & - & 1.0 & 3.4 & - & - & 1.3 & -0.9 \\
\hline 1980-1995 & 13.0 & 7.1 & - & -3.6 & 3.9 & -3.5 & -3.6 & - & 4.2 & -0.5 & 2.2 & - & -0.8 & -2.1 & - & - & 1.9 & -2.1 \\
\hline 1995-2005 & 3.2 & 8.3 & 3.0 & -3.4 & -0.6 & 4.9 & -0.8 & -2.3 & 3.4 & 5.6 & -0.1 & 10.5 & 3.7 & 11.7 & -4.2 & -0.9 & 0.5 & 1.0 \\
\hline
\end{tabular}


Table A.1c Average annual growth rates energy intensity by sector for the periods 1980-2005, 1980-1995 and $1995-2005$.

\begin{tabular}{|c|c|c|c|c|c|c|c|c|c|c|c|c|c|c|c|c|c|c|}
\hline & AUT & BEL & CZE & DNK & FIN & FRA & GER & HUN & JPN & KOR & NLD & POL & PRT & SPA & SVK & SWE & UKD & USA \\
\hline \multicolumn{19}{|c|}{ RENTING, COMPUTER, R\&D, OTHER BUSINESS } \\
\hline 1980-2005 & 3.5 & 1.1 & - & -6.2 & -4.5 & -2.1 & -3.7 & - & 1.0 & 1.0 & 0.5 & - & -0.5 & -1.5 & - & - & 0.5 & -1.4 \\
\hline $1980-1995$ & 3.9 & 1.1 & - & -6.6 & -4.2 & -2.4 & -6.4 & - & 2.6 & 0.1 & 2.8 & - & 2.8 & -5.3 & - & - & 1.9 & -2.6 \\
\hline 1995-2005 & 2.8 & 1.2 & -4.8 & -5.4 & -4.9 & -1.6 & 0.4 & -7.6 & -1.3 & 2.4 & -1.4 & -3.6 & -5.4 & 4.2 & -13.1 & -4.0 & -1.6 & 0.4 \\
\hline \multicolumn{19}{|c|}{ Renting of machinery and } \\
\hline 1980-2005 & 0.1 & - & - & -14.3 & 3.3 & 9.4 & - & - & -13.1 & 7.6 & 0.4 & - & - & 0.4 & - & - & -1.4 & 2.7 \\
\hline 1980-1995 & -1.0 & - & - & -20.0 & 12.5 & 12.9 & - & - & -9.4 & 0.7 & 1.6 & - & - & -2.5 & - & - & -1.6 & 2.2 \\
\hline $1995-2005$ & 1.8 & - & 3.5 & -5.8 & -10.6 & 4.2 & -3.2 & 3.8 & -18.8 & 17.9 & -0.5 & -20.7 & -3.1 & 4.7 & 8.6 & -11.3 & -0.9 & 3.6 \\
\hline \multicolumn{19}{|c|}{ Computer and related activities } \\
\hline 1980-2005 & -1.2 & - & - & -12.1 & -5.8 & -1.5 & - & - & 3.1 & 0.3 & -2.0 & - & - & -4.4 & - & - & -0.8 & -3.2 \\
\hline 1980-1995 & 2.6 & - & - & -10.5 & -6.2 & -1.2 & - & - & 5.8 & -1.2 & -1.1 & - & - & -5.1 & - & - & -0.7 & -4.4 \\
\hline 1995-2005 & -6.9 & - & 2.9 & -14.7 & -5.1 & -2.0 & -4.9 & 4.4 & -1.1 & 2.7 & -2.8 & -4.9 & 6.2 & -3.4 & -6.0 & -1.0 & -0.9 & -1.4 \\
\hline \multicolumn{19}{|c|}{ Research and development } \\
\hline 1980-2005 & -0.5 & - & - & -3.0 & -0.9 & 0.1 & - & - & 2.5 & 0.3 & 2.5 & - & - & -3.3 & - & - & 1.8 & -2.0 \\
\hline 1980-1995 & -2.5 & - & - & -3.6 & -1.4 & -2.6 & - & - & 1.5 & -1.2 & 10.8 & - & - & -11.5 & - & - & 0.4 & -4.6 \\
\hline 1995-2005 & 2.5 & - & -2.2 & -2.0 & -0.2 & 4.1 & -5.2 & -5.3 & 3.9 & 2.7 & -4.1 & 6.0 & 1.2 & 9.0 & -1.2 & -7.7 & 4.0 & 2.0 \\
\hline \multicolumn{19}{|c|}{ Other business activities } \\
\hline 1980-2005 & 5.4 & - & - & -3.9 & -4.8 & -3.8 & - & - & 2.2 & 0.3 & 1.0 & - & - & -1.1 & - & - & 1.2 & -1.8 \\
\hline 1980-1995 & 5.3 & - & - & -4.0 & -8.6 & -4.6 & - & - & 3.1 & -1.2 & 2.3 & - & - & -5.4 & - & - & 3.7 & -3.1 \\
\hline $1995-2005$ & 5.5 & - & -5.5 & -3.7 & 0.8 & -2.7 & 2.8 & -9.9 & 0.9 & 2.7 & 0.0 & -3.3 & -6.9 & 5.3 & -20.0 & -2.3 & -2.4 & 0.2 \\
\hline \multicolumn{19}{|c|}{ HEALTH AND SOCIAL WORK } \\
\hline 1980-2005 & 3.4 & 4.7 & - & -3.3 & 3.8 & 0.6 & -4.1 & - & 2.4 & 2.9 & -0.2 & - & 2.8 & 2.0 & - & - & -0.9 & -0.3 \\
\hline 1980-1995 & 4.6 & 7.9 & - & -2.9 & 3.7 & -0.3 & -1.7 & - & 3.6 & -2.8 & 2.5 & - & 3.2 & -0.8 & - & - & -1.5 & 0.2 \\
\hline 1995-2005 & 1.6 & -0.2 & 2.1 & -4.0 & 3.9 & 1.9 & -7.7 & -4.4 & 0.6 & 11.5 & -2.3 & 1.0 & 2.1 & 6.2 & 4.8 & -0.6 & 0.1 & -1.0 \\
\hline
\end{tabular}


Table A.1d Average annual growth rates energy intensity by sector for the periods 1980-2005, 1980-1995 and 1995-2005.

\begin{tabular}{|c|c|c|c|c|c|c|c|c|c|c|c|c|c|c|c|c|c|c|}
\hline & AUT & BEL & CZE & DNK & FIN & FRA & GER & HUN & JPN & KOR & NLD & POL & PRT & SPA & SVK & SWE & UKD & USA \\
\hline \multicolumn{19}{|c|}{ OTHER COMMUNITY, SOCIAL AND PERSONAL SERVICES } \\
\hline 1980-2005 & 3.0 & 1.3 & - & -1.0 & 1.9 & -1.7 & -2.1 & - & 3.4 & 0.9 & 0.4 & - & 0.4 & 0.1 & - & - & -0.8 & -2.5 \\
\hline 1980-1995 & 3.0 & 2.0 & - & -0.1 & 2.9 & -1.5 & -3.3 & - & 4.6 & -1.0 & 1.1 & - & -0.8 & -3.6 & - & - & -0.6 & -3.5 \\
\hline 1995-2005 & 3.0 & 0.3 & 0.8 & -2.4 & 0.4 & -1.9 & -0.2 & 2.8 & 1.6 & 3.7 & -0.1 & 5.2 & 2.1 & 5.8 & -6.0 & -1.2 & -1.2 & -0.9 \\
\hline \multicolumn{19}{|c|}{ Sewage and refuse disposal, sanitation and similar activities } \\
\hline 1980-2005 & 5.4 & - & - & 0.7 & 3.6 & -16.3 & - & - & 9.0 & 11.4 & -2.7 & - & - & 3.4 & - & - & -2.2 & 1.0 \\
\hline $1980-1995$ & 6.3 & - & - & -0.2 & -0.2 & -19.2 & - & - & 13.6 & 14.9 & -4.8 & - & - & 1.1 & - & - & -3.9 & 1.1 \\
\hline 1995-2005 & 4.0 & - & 4.2 & 2.0 & 9.3 & -11.8 & 4.7 & 1.3 & 2.1 & 6.1 & -1.0 & 2.5 & 1.4 & 6.9 & 5.2 & -1.5 & 0.3 & 0.8 \\
\hline \multicolumn{19}{|c|}{ Activities of membership organizations nec } \\
\hline 1980-2005 & 1.4 & - & - & -3.7 & 4.1 & -1.5 & - & - & -0.4 & -3.6 & 0.2 & - & - & -1.3 & - & - & -0.6 & -2.8 \\
\hline 1980-1995 & 0.4 & - & - & -3.4 & 3.4 & -2.4 & - & - & -0.3 & -6.5 & 0.9 & - & - & -3.7 & - & - & -1.2 & -4.4 \\
\hline 1995-2005 & 2.8 & - & -7.3 & -4.0 & 5.1 & -0.3 & -3.2 & -3.3 & -0.5 & 0.7 & -0.4 & 3.4 & 4.0 & 2.4 & -20.3 & -0.8 & 0.3 & -0.3 \\
\hline \multicolumn{19}{|c|}{ Recreational, cultural and sporting activities } \\
\hline 1980-2005 & 5.2 & - & - & -0.3 & 0.3 & -1.2 & - & - & 4.1 & 0.7 & 1.1 & - & - & -2.5 & - & - & -0.2 & -2.1 \\
\hline 1980-1995 & 6.6 & - & - & 2.2 & -0.6 & -1.0 & - & - & 6.0 & -1.6 & 4.4 & - & - & -7.4 & - & - & 1.4 & -2.8 \\
\hline 1995-2005 & 3.2 & - & -0.3 & -3.9 & 1.8 & -1.5 & 0.2 & 2.2 & 1.2 & 4.1 & -1.6 & 1.7 & 4.0 & 4.8 & -4.5 & -2.5 & -2.5 & -1.1 \\
\hline \multicolumn{19}{|c|}{ Other service activities } \\
\hline 1980-2005 & 4.2 & - & - & -3.8 & -0.4 & 1.7 & - & - & 1.7 & -0.2 & 2.5 & - & - & 2.6 & - & - & 1.6 & -3.2 \\
\hline 1980-1995 & 5.1 & - & - & -6.4 & 12.1 & 3.8 & - & - & 1.3 & -2.1 & 2.7 & - & - & 2.0 & - & - & 2.1 & -4.1 \\
\hline 1995-2005 & 2.7 & - & 5.9 & -0.1 & -19.2 & -1.6 & -1.8 & 4.0 & 2.1 & 2.8 & 2.3 & -1.4 & 1.3 & 3.6 & -15.1 & -2.9 & 0.9 & -1.7 \\
\hline
\end{tabular}


Table A.2 a Percentage contribution of the efficiency effect (EFF) and the structural effect (STR) by sector to the average annual growth rate of service sector energy intensity per country, for the period 1980-2005.

\begin{tabular}{|c|c|c|c|c|c|c|c|c|c|c|c|c|}
\hline & \multicolumn{3}{|c|}{ Austria } & \multicolumn{3}{|c|}{ Belgium } & \multicolumn{3}{|c|}{ Denmark } & \multicolumn{3}{|c|}{ Finland } \\
\hline & EFF & STR & TOT & EFF & STR & TOT & EFF & STR & TOT & EFF & STR & TOT \\
\hline Sale, maintenance, repair motor vehicles and-cycles; retail sale of fuel & 3.3 & -2.1 & 1.3 & & & & 4.6 & -7.5 & -2.9 & 3.0 & 4.0 & 7.0 \\
\hline Other wholesale trade and commission trade & 5.3 & 4.7 & 10.0 & -84.3 & -85.5 & -169.9 & -19.0 & 7.7 & -11.3 & 38.9 & -1.7 & 37.2 \\
\hline Other retail trade; repair of household goods & 11.7 & 0.0 & 11.7 & & & & -7.4 & 0.1 & -7.3 & 1.4 & 0.9 & 2.3 \\
\hline Hotels and restaurants & 8.8 & -3.0 & 5.8 & 19.2 & -3.2 & 15.9 & 0.7 & -2.0 & -1.3 & 0.4 & -1.5 & -1.1 \\
\hline Financial intermediation, except insurance and pension funding & 3.3 & 0.5 & 3.8 & & & & -4.6 & 2.2 & -2.4 & 14.0 & -2.6 & 11.3 \\
\hline Insurance and pension funding, except compulsory social security & 0.5 & -0.3 & 0.2 & 0.8 & 7.3 & 8.1 & -3.1 & 0.7 & -2.4 & 0.4 & 0.2 & 0.6 \\
\hline Activities related to financial intermediation & 0.3 & 0.2 & 0.4 & & & & -2.3 & 0.5 & -1.8 & 0.0 & 0.4 & 0.5 \\
\hline Renting of machinery and equipment & 0.0 & 2.1 & 2.1 & & & & -3.6 & 1.3 & -2.3 & 2.2 & -1.1 & 1.1 \\
\hline Computer and related activities & -0.3 & 2.0 & 1.7 & 196 & 562 & 758 & -4.0 & 3.5 & -0.5 & -3.6 & 3.3 & -0.3 \\
\hline Research and development & 0.0 & 0.2 & 0.2 & 19.0 & 50.2 & 10.0 & -0.9 & -0.6 & -1.5 & -0.3 & 0.4 & 0.1 \\
\hline Public administration and defence; Compulsory social security & 7.0 & -2.9 & 4.0 & 74.0 & -8.1 & 65.9 & -11.0 & -5.8 & -16.8 & 20.3 & -4.0 & 16.3 \\
\hline Education & 17.1 & -2.2 & 14.9 & 30.2 & -4.6 & 25.5 & -12.9 & -3.3 & -16.3 & 8.6 & -4.0 & 4.6 \\
\hline Health and social work & 18.2 & 2.0 & 20.1 & 40.0 & 3.5 & 43.5 & -17.5 & -1.6 & -19.1 & 25.0 & -5.2 & 19.8 \\
\hline Sewage and refuse disposal, sanitation and similar activities & 6.3 & -4.6 & 1.8 & & & & 0.7 & -2.0 & -1.3 & 3.3 & 0.4 & 3.8 \\
\hline Activities of membership organizations n.e.c. & 2.7 & -2.7 & 0.0 & & 61 & & -1.3 & -0.2 & -1.4 & 13.6 & -1.8 & 11.8 \\
\hline Recreational, cultural and sporting activities & 5.0 & -0.1 & 4.9 & 14.5 & 0.1 & 20.6 & -0.3 & 0.6 & 0.3 & 1.1 & 0.4 & 1.5 \\
\hline Other service activities & 2.1 & -0.7 & 1.4 & & & & -1.3 & -0.4 & -1.7 & -0.2 & -0.4 & -0.6 \\
\hline SERVICES & 102.6 & -2.6 & 100.0 & 118.8 & -18.8 & 100.0 & -99.7 & -0.3 & -100.0 & 98.5 & 1.5 & 100.0 \\
\hline
\end{tabular}


Table A.2b Percentage contribution of the efficiency effect (EFF) and the structural effect (STR) by sector to the average annual growth rate of service sector energy intensity per country, for the period 1980-2005.

\begin{tabular}{|c|c|c|c|c|c|c|c|c|c|c|c|c|}
\hline & \multicolumn{3}{|c|}{ France } & \multicolumn{3}{|c|}{ Germany } & \multicolumn{3}{|c|}{ Japan } & \multicolumn{3}{|c|}{ Korea } \\
\hline & EFF & STR & TOT & EFF & STR & TOT & $\mathrm{EFF}$ & STR & TOT & EFF & STR & TOT \\
\hline Sale, maintenance, repair motor vehicles and-cycles; retail sale of fuel & -4.4 & 2.1 & -2.4 & & & & 1.8 & -0.5 & 1.3 & -9.5 & 6.3 & -3.3 \\
\hline Other wholesale trade and commission trade & -415.2 & 349.3 & -65.9 & -11.5 & -2.3 & -13.8 & -8.4 & 5.4 & -3.0 & -88.8 & -32.8 & -121.6 \\
\hline Other retail trade; repair of household goods & -138.1 & 103.6 & -34.4 & & & & 12.1 & -10.2 & 1.9 & -74.4 & 38.7 & -35.7 \\
\hline Hotels and restaurants & 52.5 & -8.5 & 44.0 & -3.7 & -3.3 & -7.1 & 29.0 & -19.4 & 9.6 & -330.6 & 2.8 & -327.8 \\
\hline Financial intermediation, except insurance and pension funding & -11.9 & 17.0 & 5.1 & & & & -1.6 & 2.4 & 0.8 & -4.9 & 17.0 & 12.1 \\
\hline Insurance and pension funding, except compulsory social security & 39.3 & -35.0 & 4.3 & -0.2 & -1.5 & -1.7 & -0.4 & 0.3 & -0.1 & -0.9 & 10.5 & 9.6 \\
\hline Activities related to financial intermediation & -16.5 & 20.5 & 4.1 & & & & 0.0 & 0.0 & 0.0 & - & - & - \\
\hline Renting of machinery and equipment & 19.3 & -9.7 & 9.7 & & & & -3.9 & 4.0 & 0.1 & 30.9 & -7.5 & 23.3 \\
\hline Computer and related activities & -10.1 & 10.0 & -0.1 & -140 & 77 & 72 & 3.7 & -0.4 & 3.3 & 0.6 & 12.9 & 13.5 \\
\hline Research and development & 0.5 & 12.6 & 13.1 & -14.9 & 1.1 & -1.2 & 2.4 & 1.6 & 4.0 & 1.1 & 13.5 & 14.6 \\
\hline Public administration and defence; Compulsory social security & -84.1 & 73.5 & -10.6 & -15.2 & -6.1 & -21.3 & 20.7 & -1.5 & 19.1 & 133.6 & -53.7 & 79.8 \\
\hline Education & -3.5 & 20.6 & 17.1 & -14.9 & -7.3 & -22.2 & 12.2 & -4.4 & 7.9 & 51.9 & -56.3 & -4.4 \\
\hline Health and social work & 12.1 & 37.7 & 49.8 & -21.9 & 4.3 & -17.5 & 19.9 & 2.5 & 22.5 & 134.0 & 109.5 & 243.5 \\
\hline Sewage and refuse disposal, sanitation and similar activities & -35.3 & 29.8 & -5.6 & & & & 2.1 & -0.9 & 1.2 & 15.8 & 1.8 & 17.6 \\
\hline Activities of membership organizations n.e.c. & -5.5 & 9.6 & 4.1 & -6.8 & -1.6 & -8.4 & -0.1 & -0.8 & -0.9 & -18.4 & 10.1 & -8.3 \\
\hline Recreational, cultural and sporting activities & -25.6 & 60.3 & 34.7 & & & & 16.3 & -5.0 & 11.3 & 8.3 & 34.9 & 43.1 \\
\hline Other service activities & 3.8 & -3.7 & 0.1 & & & & 4.4 & -0.8 & 3.6 & -1.0 & -3.8 & -4.7 \\
\hline SERVICES & -779.2 & 879.2 & 100.0 & -91.8 & -8.2 & -100.0 & 117.4 & -17.4 & 100.0 & -181.8 & 281.8 & 100.0 \\
\hline
\end{tabular}


Table A.2c Percentage contribution of the efficiency effect (EFF) and the structural effect (STR) by sector to the average annual growth rate of service sector energy intensity per country, for the period 1980-2005.*

\begin{tabular}{|c|c|c|c|c|c|c|c|c|c|c|c|c|}
\hline \multirow[t]{2}{*}{ 1980-2005 } & \multicolumn{3}{|c|}{ Netherlands } & \multicolumn{3}{|c|}{ Portugal } & \multicolumn{3}{|c|}{ Spain } & \multicolumn{3}{|c|}{ United Kingdom } \\
\hline & $\begin{array}{r}\text { EFF } \\
\text { Effect }\end{array}$ & $\begin{array}{r}\text { STR } \\
\text { Effect }\end{array}$ & $\begin{array}{r}\text { TOT } \\
\text { Effect }\end{array}$ & $\begin{array}{r}\text { EFF } \\
\text { Effect }\end{array}$ & $\begin{array}{r}\text { STR } \\
\text { Effect }\end{array}$ & $\begin{array}{r}\text { TOT } \\
\text { Effect }\end{array}$ & $\begin{array}{r}\text { EFF } \\
\text { Effect }\end{array}$ & $\begin{array}{r}\text { STR } \\
\text { Effect }\end{array}$ & $\begin{array}{r}\text { TOT } \\
\text { Effect }\end{array}$ & $\begin{array}{c}\text { EFF } \\
\text { Effect }\end{array}$ & $\begin{array}{r}\text { STR } \\
\text { Effect }\end{array}$ & $\begin{array}{r}\text { TOT } \\
\text { Effect }\end{array}$ \\
\hline Sale, maintenance, repair motor vehicles and -cycles; retail sale of fuel & 12.9 & -5.3 & 7.6 & & & & -19.8 & -16.2 & -36.0 & 3.0 & -0.9 & 2.1 \\
\hline Other wholesale trade and commission trade & -13.0 & 66.3 & 53.3 & -99.6 & -23.0 & -122.7 & -6.7 & -3.1 & -9.8 & 49.7 & -0.8 & 48.9 \\
\hline Other retail trade; repair of household goods & 4.4 & -30.9 & -26.4 & & & & 39.2 & -1.7 & 37.5 & 14.9 & 4.6 & 19.4 \\
\hline Hotels and restaurants & 49.1 & -27.8 & 21.3 & -3.0 & -7.7 & -10.7 & -7.9 & -7.3 & -15.2 & 0.1 & -6.7 & -6.7 \\
\hline Financial intermediation, except insurance and pension funding & 5.5 & 5.9 & 11.4 & & & & -13.1 & -1.4 & -14.6 & 2.9 & 2.1 & 5.0 \\
\hline Insurance and pension funding, except compulsory social security & 2.1 & -1.2 & 0.9 & 0.0 & 1.5 & 1.5 & -2.1 & 1.6 & -0.5 & -2.6 & 4.1 & 1.6 \\
\hline Activities related to financial intermediation & 2.4 & 0.1 & 2.6 & & & & -0.1 & 0.9 & 0.8 & 3.8 & 0.6 & 4.4 \\
\hline Renting of machinery and equipment & 0.3 & 3.3 & 3.6 & & & & 0.7 & 1.9 & 2.6 & -2.6 & 7.8 & 5.3 \\
\hline Computer and related activities & -3.6 & 14.1 & 10.5 & & $7_{7}$ & P & -1.9 & 3.3 & 1.4 & -1.8 & 9.0 & 7.2 \\
\hline Research and development & 7.4 & -3.5 & 3.9 & & 0.1 & -0.2 & -0.2 & 0.1 & -0.1 & 1.2 & 0.0 & 1.3 \\
\hline Public administration and defence; Compulsory social security & 90.6 & -42.6 & 47.9 & 16.5 & -0.3 & 16.2 & 58.6 & -13.6 & 45.1 & 43.4 & -35.5 & 7.9 \\
\hline Education & 15.9 & -50.5 & -34.6 & 1.7 & -1.1 & 0.6 & 38.6 & 7.2 & 45.8 & 8.5 & -12.4 & -3.9 \\
\hline Health and social work & -5.8 & -19.5 & -25.3 & 18.0 & -2.2 & 15.8 & 23.7 & -1.7 & 22.0 & -9.1 & -4.2 & -13.4 \\
\hline Sewage and refuse disposal, sanitation and similar activities & -43.3 & 27.5 & -15.8 & & & & 13.3 & -0.4 & 12.9 & -5.1 & -0.4 & -5.5 \\
\hline Activities of membership organizations n.e.c. & 0.8 & -3.0 & -2.2 & & 0 & 00 & -1.2 & 1.0 & -0.2 & -0.2 & -0.3 & -0.6 \\
\hline Recreational, cultural and sporting activities & 17.4 & -4.5 & 13.0 & & 0.2 & & -16.0 & -1.1 & -17.1 & -0.5 & 1.9 & 1.4 \\
\hline Other service activities & 11.8 & -11.7 & 0.1 & & & & 4.1 & -0.5 & 3.6 & 1.0 & -0.4 & 0.6 \\
\hline SERVICES & 147.5 & -47.5 & 100.0 & -71.4 & -28.6 & -100.0 & 100.8 & -0.8 & 100.0 & 105.5 & -5.5 & 100.0 \\
\hline
\end{tabular}

* USA data are presented in main text; they are excluded here due to limited space. 
Table A.3a Percentage contribution of the efficiency effect (EFF) and the structural effect (STR) by sector to the average annual growth rate of service sector energy intensity per country, for the period 1995-2005.

\begin{tabular}{|c|c|c|c|c|c|c|c|c|c|c|c|c|}
\hline & \multicolumn{3}{|c|}{ Austria } & \multicolumn{3}{|c|}{ Belgium } & \multicolumn{3}{|c|}{ Czech Republic } & \multicolumn{3}{|c|}{ Denmark } \\
\hline & EFF & STR & TOT & $\mathrm{EFF}$ & STR & TOT & EFF & STR & TOT & EFF & STR & TOT \\
\hline Sale, maintenance, repair motor vehicles and-cycles; retail sale of fuel & -0.1 & -1.0 & -1.1 & & & & 43.6 & -12.0 & 31.6 & -2.1 & -2.3 & -4.4 \\
\hline Other wholesale trade and commission trade & 1.5 & 3.8 & 5.4 & -135.5 & -18.6 & -154.2 & 2.3 & 99.4 & 101.7 & -16.6 & 4.2 & -12.3 \\
\hline Other retail trade; repair of household goods & 6.8 & 2.0 & 8.8 & & & & -30.1 & 26.2 & -4.0 & -7.5 & -1.3 & -8.8 \\
\hline Hotels and restaurants & 9.8 & 0.1 & 9.9 & 10.8 & -3.6 & 7.2 & -5.2 & -19.4 & -24.5 & -1.9 & -4.3 & -6.1 \\
\hline Financial intermediation, except insurance and pension funding & 7.7 & -0.2 & 7.4 & & & & -1.4 & 1.9 & 0.6 & -4.0 & 1.8 & -2.2 \\
\hline Insurance and pension funding, except compulsory social security & 0.5 & -1.1 & -0.6 & -5.8 & 2.5 & -3.4 & 4.8 & -2.1 & 2.7 & -0.9 & 0.2 & -0.7 \\
\hline Activities related to financial intermediation & 0.3 & 0.6 & 0.9 & & & & - & - & - & -0.2 & 0.0 & -0.2 \\
\hline Renting of machinery and equipment & 0.9 & 2.0 & 2.9 & & & & 0.7 & 0.9 & 1.7 & -0.5 & 0.1 & -0.4 \\
\hline Computer and related activities & -3.1 & 4.7 & 1.6 & 66 & 163 & 220 & 0.9 & 1.8 & 2.7 & -4.6 & 3.4 & -1.2 \\
\hline Research and development & 0.2 & 0.1 & 0.4 & 0.0 & 10.5 & 2.9 & -0.8 & -2.0 & -2.8 & -0.3 & 0.1 & -0.2 \\
\hline Public administration and defence; Compulsary social secturity & 9.5 & -7.9 & 1.6 & 24.1 & -2.2 & 21.9 & 11.1 & -3.6 & 7.5 & -4.6 & -4.9 & -9.5 \\
\hline Education & 12.2 & -2.7 & 9.5 & 11.8 & -2.6 & 9.3 & 9.9 & 1.2 & 11.1 & -8.3 & -3.1 & -11.4 \\
\hline Health and social work & 12.0 & 2.4 & 14.4 & -0.7 & -1.1 & -1.8 & 8.5 & -18.3 & -9.8 & -15.7 & -2.7 & -18.4 \\
\hline Sewage and refuse disposal, sanitation and similar activities & 5.4 & -3.9 & 1.5 & & & & 5.8 & -3.8 & 2.0 & 2.2 & -6.6 & -4.4 \\
\hline Activities of membership organizations nec & 5.3 & -3.3 & 2.0 & & & & -2.9 & -0.3 & -3.1 & -1.0 & -0.4 & -1.5 \\
\hline Recreational, cultural and sporting activities & 4.7 & -0.6 & 4.1 & 1 & -3.1 & -2.8 & -0.4 & 2.5 & 2.1 & -5.6 & -1.8 & -7.5 \\
\hline Other service activities & 1.7 & -0.3 & 1.5 & & & & 4.3 & -3.7 & 0.6 & 0.0 & -0.5 & -0.5 \\
\hline SERVICES & 99.8 & 0.2 & 100.0 & -90.5 & -9.5 & -100.0 & 20.7 & 79.3 & 100.0 & -85.5 & -14.5 & -100.0 \\
\hline
\end{tabular}


Table A.3b Percentage contribution of the efficiency effect (EFF) and the structural effect (STR) by sector to the average annual growth rate of Services energy intensity per country, for the period 1995-2005.

\begin{tabular}{|c|c|c|c|c|c|c|c|c|c|c|c|c|}
\hline \multirow[t]{2}{*}{ 1995-2005 } & \multicolumn{3}{|c|}{ Finland } & \multicolumn{3}{|c|}{ France } & \multicolumn{3}{|c|}{ Germany } & \multicolumn{3}{|c|}{ Hungary } \\
\hline & $\mathrm{EFF}$ & STR & TOT & $\mathrm{EFF}$ & STR & TOT & EFF & STR & TOT & $\mathrm{EFF}$ & STR & TOT \\
\hline Sale, maintenance, repair motor vehicles and-cycles; retail sale of fuel & 0.6 & 10.4 & 11.0 & -14.6 & -36.6 & -51.2 & -1.4 & 2.4 & 1.1 & -0.2 & 1.4 & 1.3 \\
\hline Other wholesale trade and commission trade & 48.0 & 26.7 & 74.7 & -215.0 & 174.7 & -40.3 & -38.1 & 2.2 & -35.9 & -90.4 & 6.5 & -83.9 \\
\hline Other retail trade; repair of household goods & 1.5 & 7.1 & 8.6 & -29.9 & -49.0 & -78.9 & 9.9 & -7.0 & 3.0 & 8.5 & -0.2 & 8.3 \\
\hline Hotels and restaurants & -0.3 & -1.7 & -2.0 & 35.5 & -21.0 & 14.6 & -5.0 & -2.6 & -7.6 & -2.3 & -2.1 & -4.4 \\
\hline Financial intermediation, except insurance and pension funding & 18.5 & -23.5 & -4.9 & -1.5 & 9.5 & 8.0 & 1.5 & 0.7 & 2.2 & -0.9 & 0.1 & -0.8 \\
\hline Insurance and pension funding, except compulsory social security & 5.8 & -0.3 & 5.6 & 27.5 & -26.3 & 1.2 & 9.8 & -8.3 & 1.5 & -0.6 & 0.3 & -0.3 \\
\hline Activities related to financial intermediation & 0.6 & 0.4 & 1.0 & -9.3 & 16.6 & 7.3 & 2.4 & -1.6 & 0.8 & 0.2 & 0.3 & 0.5 \\
\hline Renting of machinery and equipment & -13.2 & 3.1 & -10.1 & 15.1 & -6.7 & 8.3 & -1.3 & 1.2 & -0.1 & 0.5 & -0.3 & 0.2 \\
\hline Computer and related activities & -2.6 & 3.9 & 1.3 & -14.6 & 19.9 & 5.4 & -2.9 & 3.7 & 0.8 & 0.3 & 0.9 & 1.2 \\
\hline Research and development & -0.1 & 0.2 & 0.1 & 40.5 & -33.9 & 6.6 & -4.0 & 1.4 & -2.6 & -1.4 & -0.4 & -1.7 \\
\hline Public administration and defence; Compulsory social security & 28.1 & -11.7 & 16.4 & -19.5 & -40.0 & -59.5 & 6.1 & -12.5 & -6.4 & 0.5 & -1.8 & -1.3 \\
\hline Education & -3.4 & -8.4 & -11.8 & 124.9 & -52.7 & 72.2 & -5.8 & -8.6 & -14.4 & -2.4 & 0.0 & -2.5 \\
\hline Health and social work & 32.6 & -15.9 & 16.7 & 55.3 & -25.7 & 29.5 & -64.4 & 17.4 & -47.0 & -4.4 & 0.1 & -4.4 \\
\hline Sewage and refuse disposal, sanitation and similar activities & 9.4 & -1.5 & 7.8 & -28.9 & 14.1 & -14.8 & 2.7 & -3.5 & -0.7 & 0.7 & 0.0 & 0.8 \\
\hline Activities of membership organizations n.e.c. & 19.8 & -0.5 & 19.3 & -1.3 & -3.5 & -4.8 & -1.7 & -0.5 & -2.2 & -0.4 & -0.1 & -0.5 \\
\hline Recreational, cultural and sporting activities & 6.2 & -4.9 & 1.3 & -41.1 & 72.5 & 31.4 & 0.5 & 0.4 & 0.9 & 1.0 & -1.7 & -0.7 \\
\hline Other service activities & -27.8 & -0.4 & -28.2 & -4.7 & -3.2 & -7.9 & -2.6 & -1.3 & -3.9 & 1.0 & -1.1 & -0.1 \\
\hline SERVICES & 103.9 & -3.9 & 100.0 & -278.1 & 178.1 & -100.0 & -84.8 & -15.2 & -100.0 & -103.3 & 3.3 & -100.0 \\
\hline
\end{tabular}


Table A.3c Percentage contribution of the efficiency effect (EFF) and the structural effect (STR) by sector to the average annual growth rate of service sector energy intensity per country, for the period 1995-2005.

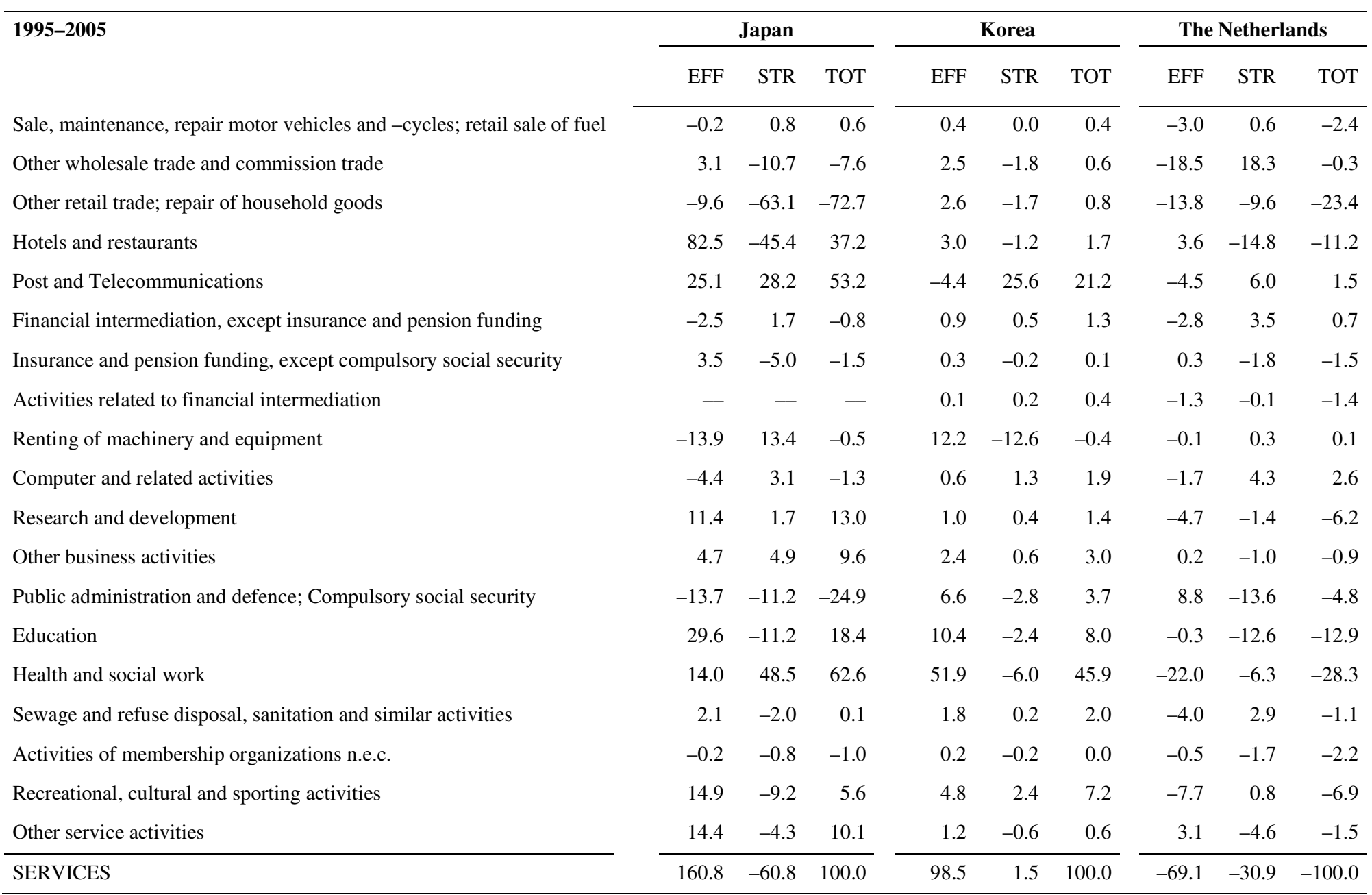


Table A.3d Percentage contribution of the efficiency effect (EFF) and the structural effect (STR) by sector to the average annual growth rate of service sector energy intensity per country, for the period 1995-2005.

\begin{tabular}{|c|c|c|c|c|c|c|c|c|c|c|c|c|}
\hline & \multicolumn{3}{|c|}{ Poland } & \multicolumn{3}{|c|}{ Portugal } & \multicolumn{3}{|c|}{ Slovakia } & \multicolumn{3}{|c|}{ Spain } \\
\hline & EFF & STR & TOT & $\mathrm{EFF}$ & STR & TOT & $\mathrm{EFF}$ & STR & TOT & EFF & STR & TOT \\
\hline Sale, maintenance, repair motor vehicles and-cycles; retail sale of fuel & -120.8 & 49.7 & -71.1 & -24.6 & -8.6 & -33.2 & -0.8 & 2.4 & 1.6 & 2.7 & -0.4 & 2.3 \\
\hline Other wholesale trade and commission trade & -116.4 & 234.5 & 118.1 & 12.3 & -6.4 & 5.9 & -10.1 & 9.7 & -0.3 & 7.4 & 0.2 & 7.6 \\
\hline Other retail trade; repair of household goods & -327.5 & -106.1 & -433.6 & 19.2 & 7.2 & 26.4 & -59.6 & 12.8 & -46.8 & 19.1 & -0.6 & 18.5 \\
\hline Hotels and restaurants & -66.5 & 34.7 & -31.9 & -41.9 & -23.1 & -65.0 & 6.2 & -14.2 & -8.0 & 1.7 & -1.9 & -0.2 \\
\hline Financial intermediation, except insurance and pension funding & 54.7 & 96.0 & 150.7 & -8.5 & 8.7 & 0.2 & -2.5 & -3.5 & -5.9 & -3.0 & 0.6 & -2.4 \\
\hline Insurance and pension funding, except compulsory social security & 187.7 & 113.6 & 301.3 & -1.2 & -0.7 & -1.9 & 0.5 & -0.5 & 0.0 & -0.1 & 0.4 & 0.3 \\
\hline Activities related to financial intermediation & -57.4 & 12.5 & -44.9 & 0.0 & 0.0 & 0.0 & - & - & - & -0.1 & -0.3 & -0.3 \\
\hline Renting of machinery and equipment & -56.8 & 34.0 & -22.8 & -1.9 & 0.8 & -1.1 & 0.5 & -0.4 & 0.1 & 1.4 & 0.1 & 1.5 \\
\hline Computer and related activities & -17.7 & 35.6 & 17.9 & 3.0 & 1.2 & 4.1 & -0.9 & 0.3 & -0.6 & -0.3 & 0.6 & 0.2 \\
\hline Research and development & 36.1 & -51.6 & -15.5 & 0.3 & -0.2 & 0.1 & -0.3 & -3.9 & -4.1 & 0.1 & 0.0 & 0.1 \\
\hline Public administration and defence; Compulsory social security & 53.8 & -0.9 & 52.9 & -26.3 & -5.4 & -31.7 & -14.5 & 6.8 & -7.7 & 17.2 & -2.8 & 14.4 \\
\hline Education & 386.0 & -63.2 & 322.8 & 13.8 & -6.9 & 6.9 & -6.5 & -0.7 & -7.2 & 22.8 & -1.6 & 21.2 \\
\hline Health and social work & 47.8 & -167.3 & -119.4 & 41.2 & -19.1 & 22.1 & 6.2 & -7.0 & -0.9 & 12.1 & -0.2 & 11.9 \\
\hline Sewage and refuse disposal, sanitation and similar activities & 67.8 & 134.2 & 202.0 & 1.0 & 0.3 & 1.4 & 2.3 & -4.1 & -1.9 & 4.7 & 1.3 & 6.0 \\
\hline Activities of membership organizations n.e.c. & 41.7 & -14.4 & 27.4 & 16.8 & -12.0 & 4.8 & -4.7 & 3.2 & -1.5 & 0.3 & 0.1 & 0.4 \\
\hline Recreational, cultural and sporting activities & 32.2 & 32.8 & 65.0 & 5.8 & -0.2 & 5.6 & -2.5 & -1.1 & -3.6 & 3.0 & -0.1 & 2.9 \\
\hline Other service activities & -9.5 & -96.1 & -105.6 & 1.2 & 0.3 & 1.5 & -3.1 & 1.3 & -1.8 & 1.0 & 0.3 & 1.3 \\
\hline SERVICES & -368.3 & 468.3 & 100.0 & -31.9 & -68.1 & -100.0 & -112.3 & 12.3 & -100.0 & 100.9 & -0.9 & 100.0 \\
\hline
\end{tabular}


Table A.3e Percentage contribution of the efficiency effect (EFF) and the structural effect (STR) by sector to the average annual growth rate of service sector energy intensity per country, for the period 1995-2005.

\begin{tabular}{|c|c|c|c|c|c|c|c|c|c|}
\hline & \multicolumn{3}{|c|}{ Sweden } & \multicolumn{3}{|c|}{ United Kingdom } & \multicolumn{3}{|c|}{ USA } \\
\hline & $\mathrm{EFF}$ & STR & TOT & $\mathrm{EFF}$ & STR & TOT & $\mathrm{EFF}$ & STR & TOT \\
\hline Sale, maintenance, repair motor vehicles and-cycles; retail sale of fuel & -3.7 & 1.3 & -2.4 & 131.0 & -32.1 & 99.0 & -32.3 & 23.2 & -9.0 \\
\hline Other wholesale trade and commission trade & -29.0 & 10.3 & -18.7 & 253.7 & -125.8 & 127.9 & -15.9 & -4.5 & -20.4 \\
\hline Other retail trade; repair of household goods & -10.5 & 3.7 & -6.8 & 126.7 & -14.5 & 112.2 & -51.4 & 25.5 & -25.9 \\
\hline Hotels and restaurants & -0.7 & -0.3 & -1.1 & 74.3 & -31.3 & 42.9 & -7.1 & -8.1 & -15.2 \\
\hline Post and Telecommunications & -7.2 & 4.2 & -3.0 & -117.4 & 157.8 & 40.4 & -4.6 & 3.8 & -0.8 \\
\hline Financial intermediation, except insurance and pension funding & -0.3 & 0.5 & 0.2 & -157.4 & 64.7 & -92.7 & -7.5 & 7.0 & -0.5 \\
\hline Insurance and pension funding, except compulsory social security & -1.1 & -1.2 & -2.3 & 73.7 & -107.0 & -33.2 & 0.5 & -1.4 & -0.9 \\
\hline Activities related to financial intermediation & 0.0 & 0.1 & 0.1 & 6.2 & 14.8 & 20.9 & - & - & - \\
\hline Renting of machinery and equipment & -4.6 & 1.7 & -2.9 & -14.2 & 11.8 & -2.4 & 6.9 & -4.4 & 2.5 \\
\hline Computer and related activities & -0.3 & 0.9 & 0.6 & -12.9 & 90.5 & 77.6 & -1.0 & 2.7 & 1.7 \\
\hline Research and development & -1.6 & 1.5 & -0.2 & 17.6 & -9.5 & 8.0 & 1.1 & 0.2 & 1.3 \\
\hline Other business activities & -4.1 & -0.9 & -5.0 & -93.6 & 106.0 & 12.5 & 1.0 & 1.4 & 2.5 \\
\hline Public administration and defence; Compulsory social security & -10.4 & -20.8 & -31.1 & 192.7 & -253.6 & -60.9 & 9.3 & -26.7 & -17.5 \\
\hline Education & -2.0 & -3.2 & -5.1 & 19.3 & -118.2 & -98.9 & 1.0 & -1.1 & -0.1 \\
\hline Health and social work & -2.8 & -8.5 & -11.3 & 3.8 & -56.3 & -52.5 & -5.4 & -0.7 & -6.1 \\
\hline Sewage and refuse disposal, sanitation and similar activities & -1.5 & 2.1 & 0.6 & 3.2 & -25.6 & -22.4 & 1.4 & -4.7 & -3.3 \\
\hline Activities of membership organizations n.e.c. & -1.3 & -4.7 & -5.9 & 0.6 & -10.8 & -10.2 & -1.0 & -2.6 & -3.5 \\
\hline Recreational, cultural and sporting activities & -5.1 & 0.0 & -5.0 & -51.1 & -5.2 & -56.3 & -2.4 & 1.4 & -1.0 \\
\hline Other service activities & -0.6 & -0.1 & -0.7 & 4.1 & -16.1 & -11.9 & -2.7 & -1.0 & -3.7 \\
\hline SERVICES & -86.7 & -13.3 & -100.0 & 460.4 & -360.4 & 100.0 & -110.1 & 10.1 & -100.0 \\
\hline
\end{tabular}


Table A.4. Country fixed effects (extending Table 12 in the main text)

\begin{tabular}{|c|c|c|c|c|c|c|c|c|c|c|c|c|}
\hline Sector & TRA & HOT & TEL & FIN & OBU & $\mathrm{ADM}$ & EDU & HEA & SOC & SRV & MAN & TOT \\
\hline AUT & 0.154 & 0.084 & -0.042 & 0.347 & 0.473 & -0.353 & 0.072 & -0.080 & -0.016 & 0.072 & 0.174 & 0.138 \\
\hline BEL & -0.278 & 0.014 & -0.219 & 0.118 & -0.182 & 0.196 & 0.383 & 0.185 & -0.182 & 0.000 & -0.300 & -0.227 \\
\hline CZE & -0.556 & -0.245 & 0.123 & -0.081 & 0.083 & -0.241 & -0.421 & 0.077 & 0.107 & 0.019 & 0.006 & 0.069 \\
\hline DNK & -0.166 & -0.079 & 0.187 & 0.176 & 0.132 & 0.426 & 0.873 & 0.307 & 0.058 & 0.232 & 0.508 & 0.377 \\
\hline FIN & -0.819 & -0.239 & 0.952 & 0.270 & 1.007 & 0.309 & 2.136 & 0.716 & 0.077 & 0.569 & 0.061 & 0.281 \\
\hline FRA & -0.069 & 0.137 & -0.045 & -0.154 & -0.343 & 0.436 & -0.220 & 0.328 & 0.009 & -0.037 & -0.094 & \\
\hline GER & 0.373 & -0.060 & -0.166 & -0.306 & 0.056 & 0.418 & -0.416 & 0.089 & 0.347 & 0.121 & 0.056 & 0.024 \\
\hline HUN & -0.218 & 0.291 & 0.071 & 0.248 & -0.075 & -0.794 & -0.195 & 0.241 & -0.199 & 0.144 & 0.384 & 0.355 \\
\hline JPN & 0.593 & -0.321 & -0.625 & 0.100 & -0.545 & -0.094 & -0.447 & -0.321 & -0.152 & -0.158 & 0.006 & -0.235 \\
\hline KOR & 0.358 & -0.198 & -0.566 & -0.026 & -0.564 & -0.749 & -0.546 & -1.051 & -0.208 & -0.300 & -0.467 & -0.222 \\
\hline NLD & 0.370 & -0.480 & 0.426 & 0.014 & -0.015 & 0.250 & 0.173 & 0.231 & -0.361 & 0.063 & -0.112 & -0.135 \\
\hline PRT & 0.245 & 0.321 & 0.214 & 0.426 & -0.127 & -0.888 & -1.015 & -0.763 & -0.036 & -0.214 & -0.184 & -0.112 \\
\hline SPA & -0.210 & 0.905 & -0.044 & -0.129 & 0.050 & -0.267 & -1.167 & 0.001 & 0.408 & -0.082 & -0.055 & 0.058 \\
\hline SWE & -0.050 & -0.579 & 0.375 & 0.193 & 0.199 & 0.120 & 0.810 & 0.220 & -0.259 & 0.270 & 0.286 & 0.136 \\
\hline UK & -0.031 & 0.264 & 0.130 & -0.689 & 0.114 & 0.429 & -0.132 & 0.288 & 0.466 & -0.018 & 0.001 & 0.080 \\
\hline USA & -0.041 & -0.223 & -0.212 & -0.294 & -0.110 & 0.362 & 0.447 & 0.000 & -0.308 & -0.148 & -0.158 & -0.279 \\
\hline
\end{tabular}

Notes: The country fixed effects are centered around zero. The sectors are labeled as follows: TRA: Wholesale and retail trade; HOT: Hotels and restaurants; TEL: Post and telecommunications; FIN: Financial intermediation; OBU: Renting, computer, R\&D and other business; ADM: Public admin and defence; compulsory social security; EDU:

Education; HEA: Health and social work; SOC: Other community, social and personal services; SRV: Services; MAN: Manufacturing; TOT: Aggregate economy. 